\title{
SYMBOLIC PLAY IN CHILDREN WITH AUTISM SPECTRUM DISORDER
}

\author{
A Thesis \\ Presented to
}

The Faculty of Graduate Studies

of

The University of Guelph

by

\section{GILLIAN STANLEY}

In partial fulfillment of requirements

for the degree of

Master of Arts

October, 2004

(C) Gillian Stanley, 2004 


$\begin{array}{ll}\begin{array}{l}\text { Library and } \\ \text { Archives Canada }\end{array} & \begin{array}{l}\text { Bibliothèque et } \\ \text { Archives Canada }\end{array} \\ \begin{array}{l}\text { Published Heritage } \\ \text { Branch }\end{array} & \begin{array}{l}\text { Direction du } \\ \text { Patrimoine de l'édition }\end{array} \\ \begin{array}{l}\text { 395 Wellington Street } \\ \text { Ottawa ON K1A ON4 }\end{array} & \begin{array}{l}\text { 395, rue Wellington } \\ \text { Ottawa ON K1A ON4 }\end{array} \\ \text { Canada } & \text { Canada }\end{array}$

Yourfile Votre référence

ISBN: 0-494-01863-1

Ourfile Notre référence

ISBN: 0-494-01863-1

NOTICE:

The author has granted a nonexclusive license allowing Library and Archives Canada to reproduce, publish, archive, preserve, conserve, communicate to the public by telecommunication or on the Internet, loan, distribute and sell theses worldwide, for commercial or noncommercial purposes, in microform, paper, electronic and/or any other formats.

The author retains copyright ownership and moral rights in this thesis. Neither the thesis nor substantial extracts from it may be printed or otherwise reproduced without the author's permission.
AVIS:

L'auteur a accordé une licence non exclusive permettant à la Bibliothèque et Archives Canada de reproduire, publier, archiver, sauvegarder, conserver, transmettre au public par télécommunication ou par l'Internet, prêter, distribuer et vendre des thèses partout dans le monde, à des fins commerciales ou autres, sur support microforme, papier, électronique et/ou autres formats.

L'auteur conserve la propriété du droit d'auteur et des droits moraux qui protège cette thèse. $\mathrm{Ni}$ la thèse ni des extraits substantiels de celle-ci ne doivent être imprimés ou autrement reproduits sans son autorisation.
In compliance with the Canadian

Privacy Act some supporting forms may have been removed from this thesis.

While these forms may be included in the document page count, their removal does not represent any loss of content from the thesis.
Conformément à la loi canadienne sur la protection de la vie privée, quelques formulaires secondaires ont été enlevés de cette thèse.

Bien que ces formulaires aient inclus dans la pagination, il n'y aura aucun contenu manquant.

\section{Canadä}




\section{ABSTRACT \\ SYMBOLIC PLAY IN CHILDREN WITH AUTISM SPECTRUM DISORDER \\ Gillian Stanley \\ University of Guelph, 2004 \\ Advisor: \\ Professor M. M. Konstantareas}

The relationship between symbolic play and other developmental domains, such as autistic symptomatology, nonverbal cognitive ability, receptive language, expressive language, and social development, was investigated. The assessment files of 101 children with Autism Spectrum Disorder (ASD) were studied. It was found that level of symbolic play was most strongly related to nonverbal cognitive ability, followed by autistic symptomatology. Symbolic play was also related to expressive but not receptive language. Interestingly, social development was significantly related to symbolic play in a subset of children with high nonverbal cognitive ability, relative to the entire sample, but not in the corresponding subset with low nonverbal cognitive ability. Further, an exploration of the relation between expressive language and social development provided preliminary evidence that expressive language mediates the relationship between social development and symbolic play. 


\section{Acknowledgements}

I would like to thank my advisor, Dr. Mary Konstantareas, for all of her help and support throughout this process. Despite the many challenges we encountered, she has always been there to encourage and inspire me. Her knowledge in the area has been invaluable. I would also like to take this opportunity to thank Dr. Karl Hennig, my thesis committee member, for all of his suggestions and support, and for being willing to step up to the challenge of this topic. Dr. Marcia Barnes also deserves a special thank you for her swift and thorough review of my thesis, as well as her insightful comments.

My thanks also go out to all the children who were involved in this study, and to their parents for providing much of the information. Without them, this study would not have been possible.

My sincere gratitude also belongs to the faculty and staff of the Department of Psychology. Robin Fraser, the graduate secretary, deserves extra thanks for her willingness to just drop everything in order to help me. Having an ally such as her has made this process infinitely easier. And to my cohort, Ali Blakely, Carol-Anne Hendry, Jen Lasenby, Andrea McClure, Melanie Parkin, Kate Spere, and Melissa Wells, a special thanks to you all for being there to join me on my various crusades. You all understand what I mean.

Lastly, my parents and outside friends deserve huge congratulations for having supported me for the past 25 years. My current achievements may be credited to your efforts and encouragement.

Thanks. 


\section{Table of Contents}

List of Tables $\quad$.............................................................. iv

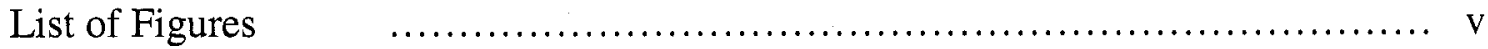

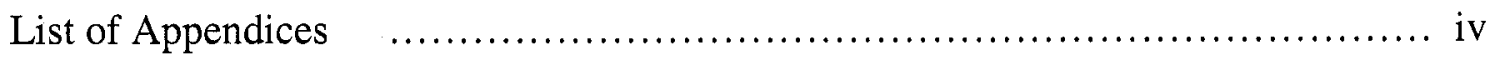

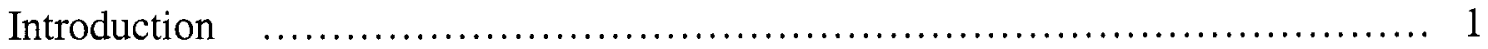

Definitional Issues in Symbolic Play $\quad$.............................. 2

Autism Spectrum Disorder and Symbolic Play $\quad \ldots \ldots \ldots \ldots \ldots \ldots \ldots \ldots \ldots \ldots$

Cognitive Development and Symbolic Play $\quad \ldots \ldots \ldots \ldots \ldots \ldots \ldots \ldots \ldots$

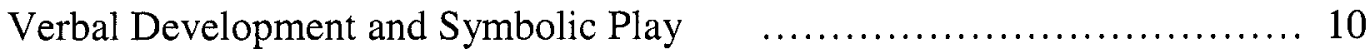

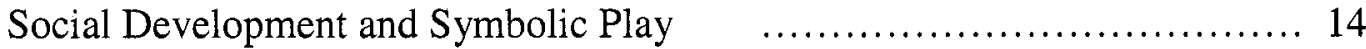

Methodological Considerations in the Study of Autism Spectrum Disorder ... 20

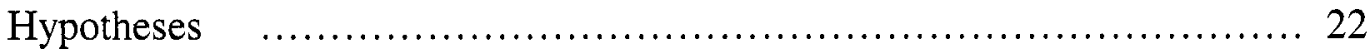

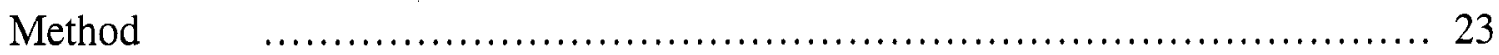

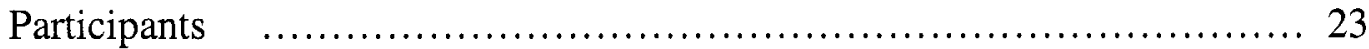

Measures $\quad$.............................................................. 24

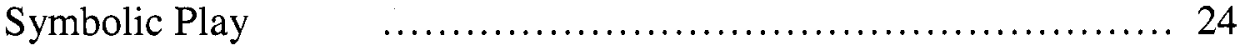

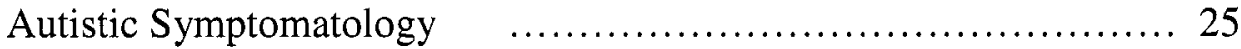

Nonverbal Cognitive Ability $\quad$............................ 26

Verbal Ability $\quad$........................................... 29

Social Development $\quad$................................... 30

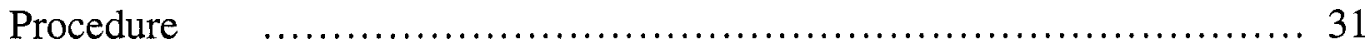


Results

Preliminary Analyses $\quad$..................................... 34

Predictors of Symbolic Play $\quad$.................................. 34

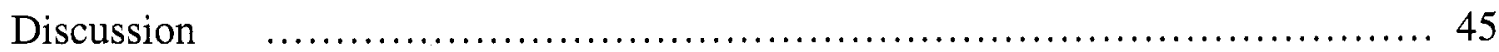

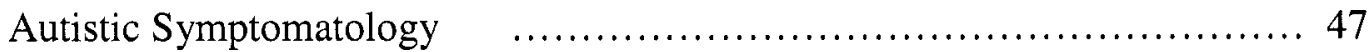

Nonverbal Cognitive Ability and Symbolic Play $\quad \ldots \ldots \ldots \ldots \ldots \ldots \ldots \ldots 47$

Verbal Ability and Symbolic Play $\quad \ldots \ldots \ldots \ldots \ldots \ldots \ldots \ldots \ldots \ldots \ldots \ldots \ldots \ldots$

Social Development and Symbolic Play $\quad \ldots \ldots \ldots \ldots \ldots \ldots \ldots \ldots \ldots \ldots . \ldots \ldots$

Interaction between Social Development and Expressive Language ......... 54

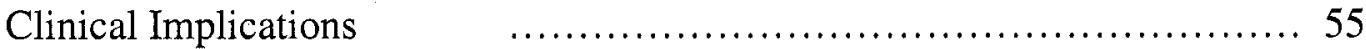

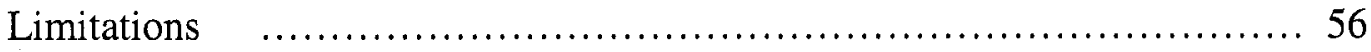

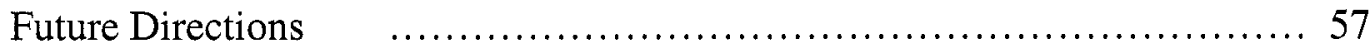

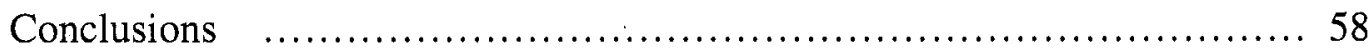

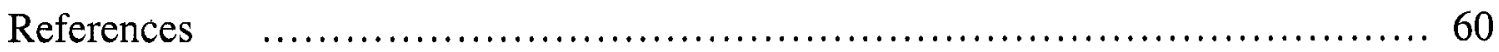

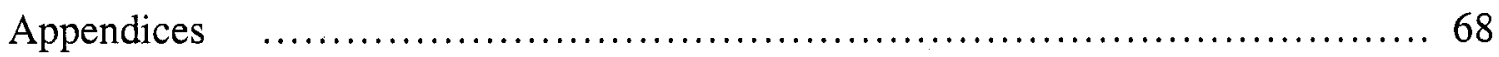




\section{List of Tables}

Table 1 Descriptives for Chronological Age, Symbolic

Play Age, Autistic Symptomatology, Nonverbal

Cognitive Ability, Expressive Language,

Receptive Language, Receptive Vocabulary,

and Social Development

Table 2 Intercorrelation Matrix of Key Independent

Variables for Total Sample Intercorrelation

Table 3 Hierarchical Regression Analysis with Autistic

Symptomatology Predicting Symbolic Play

Development

Table 4 Hierarchical Regression Analysis with Nonverbal

Cognitive Ability Predicting Symbolic Play

Development

Table 5 Hierarchical Regression Analysis with Receptive

Language Predicting Symbolic Play Development

Table 6 Hierarchical Regression Analysis with Expressive

Language Predicting Symbolic Play Development

Table 7 Hierarchical Regression Analysis with Social

Development Predicting Symbolic Play

Development 


\section{List of Figures}

Figure 1 Scatterplot showing the relationship between Play

Age Log and Social Development Age Log for

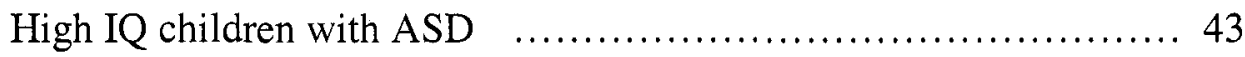

Figure 2 Scatterplot showing the relationship between Play

Age Log and Social Development Age Log for

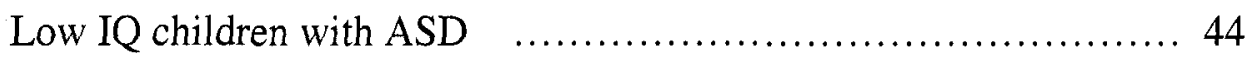

Figure 3 Expressive language as the mediator of the

relationship between social development and

symbolic play 


\section{List of Appendices}

Appendix A

Parental Consent Form

68

Appendix B

Symbolic Play Test Items

69 


\section{Introduction}

Almost all children play. Despite the recent proliferation of studies investigating children's play, there is as yet no clear description of how play develops. Several possibilities have been proposed, but none is currently dominant in the field of child development. A new and promising area of investigation into the development of play is found in the literature on Autism Spectrum Disorder (ASD), as it is widely accepted that one of the impairments shown by children with ASD is an impairment in play ability. ASD is a recent term that is more inclusive than Autistic Disorder or Pervasive Developmental Disorder (APA, DSM-IV-TR, 2000). Henceforth, in this thesis, the term will be employed to refer to literature for which the term Autistic Disorder was used in the past.

Children with similar levels of autistic symptomatology can have very different developmental profiles across specific domains. It is important to examine these domains for their relationship to symbolic play in order to obtain a more complete picture of the factors that influence play development in this atypical population. These relationships may be of relevance to symbolic play development in typical children. The purpose of the current study is to examine the relationship between symbolic play and autistic symptomatology, as well as other functional domains in a group of children with ASD. Specifically, the current study builds on previous research that suggests that symbolic play is related to nonverbal cognitive ability, expressive and receptive language, and social development. In doing so, it may be possible to contribute to a coherent understanding of the mechanisms through which play develops in both atypical and typical populations. 


\section{Definitional issues in Symbolic Play}

Play is hard to define, and the same play behaviours have been classified as both functional and symbolic, depending on the definition. The most commonly accepted definition of functional play is that summarized by Lewis and Boucher (1988). They stated that functional play is play in which objects, including miniature representations of real objects, are used in ways appropriate to their conventional function. Symbolic play, in contrast, is defined as that in which one of three conditions is met: an object has been substituted for another one, an object has been assigned attributes that it does not have, or absent objects are referred to as if they were present (Baron-Cohen, 1987). In order for play to be symbolic, the child must know what the object is, what its attributes are, and then assign it attributes it does not have. These definitions provide a beginning point for the investigation of play and its two presumably distinct forms. In practice, however, previous research has often relied on the spontaneous verbalizations of the player to aid in distinguishing between functional and symbolic play acts. The functional action of rocking a doll, for example, becomes symbolic if the player says, "Stop crying." Although this approach may be useful in understanding the play of speaking children, it may be problematic when studying play in children with $\mathrm{ASD}, 50 \%$ of whom are nonverbal. Even those who do talk are impaired in their ability to employ language spontaneously (Gould, 1986).

In terms of tasks that measure types of play, the symbolic Play Test, or SPT (Lowe \& Costello, 1976), has often been used and is used in the current study. According to Baron-Cohen's (1987) definition of play, the SPT may be a measure of functional play as opposed to symbolic play. The test's claim to symbolism, according to 
Baron-Cohen (1987), was based on the assumption that children recognize realistic miniature objects as symbols of real objects and use them accordingly, which may be false, as children may simply perceive the objects to be real little objects. However, Vondra and Belsky (1991) contested this argument, claiming that play with miniature objects is in fact symbolic, regardless of whether or not children understand that the miniature objects are symbols, since the acts are decontextualized. As well, the toys used as stimuli for the SPT can elicit both functional play and more creative symbolic play from children. Thus, although there is some debate as to whether this test measures purely symbolic or functional play, it will be assumed for the current study that the SPT is a measure of concept formation and symbol use, or symbolic play as defined above (Lowe \& Costello, 1976).

Libby, Powell, Messer, \& Jordan (1998) used the term "pretend play" as an umbrella term for both functional and symbolic play. They noted that pretend play involves processes that are symbolic, and so using pretend play as synonymous with symbolic play, as has been done in previous research (e.g., Baron-Cohen, 1987), may be misleading. Because of the difficulties in differentiating between functional and symbolic play, as well as the difficulties children with ASD have with spontaneous expressive language, this study follows Libby et al.'s initiative in not distinguishing between functional and symbolic play. The term "symbolic play" will be used to encompass both functional and symbolic play.

Piaget is generally considered to be the pioneer of the study of play. Based on intensive observation of his own children, Piaget outlined the development of play (Piaget, 1962). In his original conceptions, he described six stages through which 
children pass as they develop true symbolic representational ability. It is during the second stage, that of primary circular reactions, that actions can begin to be seen that resemble play. Piaget argued that for an action to be considered as play, it must be performed with enjoyment as its only function. As the infant progresses from the second to the sixth stage of development, he/she assimilates new information into existing schemas, and subsequently adapts those schemas to accommodate the new information. Play evolves as a continuation of assimilation, while imitation evolves as a continuation of accommodation. According to this view, play arises when assimilation is no longer adaptive, but rather is a playful manifestation. The child applies existing schemas to new objects and behaviours in a ritualistic manner, which is a form of pre-symbolic play. As the playful action becomes less of a habitual sequence of actions and more of a symbol of an action or event, pretence and symbolism evolve. Thus, according to Piaget, symbolic schemas are necessary to enable symbolic play, and these schemas arise from a dissociation between repetitive habitual actions and the representation of the event.

Fein (1981) and Jarrold, Boucher, \& Smith (1993) described three main developmental trends in symbolic representation in typically developing children. Initially, the child begins to use objects in a self-oriented manner. Gradually, as the child develops, decentration occurs. Decentration involves a moving away from the self as agent in pretend situations to other as agent, i.e., from pretending to feed one's self to pretending to feed one's parent or a doll, and is typically seen when the child begins to incorporate other individuals or dolls into his/her play. The second trend is decontextualization, which involves the moving away from using realistic objects in pretence. Objects that were previously avoided because they were unrepresentative are 
now incorporated into play to stand for other absent objects. This is followed by integration, the combining of individual symbolic acts to form sequences.

Symbolic play is seen in almost all children, and most go through a similar sequence in the development of play. For example, children who are mentally retarded follow the same developmental sequence as children who are normally developing, although their progression is generally delayed when compared with typical children (Power \& Radcliffe, 1989). The continuity in these developmental trends further supports the use of the blanket term "symbolic play", as adopted in this study, rather than separating what may be two intrinsically related concepts.

Autism Spectrum Disorder and Symbolic Play

ASD is a lifelong developmental disorder that affects all areas of functioning. It is characterized by a triad of features: a qualitative impairment in social interaction, a qualitative impairment in communication, and restricted repetitive and stereotyped patterns of interest (APA, 2000). The age of onset must be prior to three years, and is frequently identifiable as early as 6 months, although diagnosis is more reliable in older children. Many children with ASD also present with mild to severe mental retardation; in fact, (Fombonne, 1998) estimates that up to $80 \%$ of children with ASD are also mentally retarded. ASD affects males four to five times more frequently than females, especially amongst higher functioning individuals (Fombonne, 1999).

One of the associated diagnostic criteria for ASD in the DSM-IV-TR is inappropriate symbolic or imaginative play (APA, 2000). Typically, the play of children with ASD, if it in fact exists at all, has been thought of as simple, repetitive, and stereotyped, lacking much of the complexity and diversity that characterizes the play of 
children without ASD (Jarrold, et al., 1993; Whyte \& Owens, 1989). Sigman and Ungerer (1984b) conducted a study that supported the idea that abnormalities in symbolic play are specific to ASD. These authors found that childhood diagnosis, either ASD, mental retardation, or no diagnosis, independently predicted level of symbolic play, with children with ASD having the least symbolic play. Sigman and Ungerer (1984b) argued that deficits in symbolic play are unique to ASD, and are not accounted for by language deficits. Given that impaired symbolic play was specific to ASD, and that it is a symptom of ASD, it is therefore logical to hypothesize that more severe overall ASD symptomatology will be associated with more severe impairments in symbolic play, though this has not been tested.

Several studies have examined the characteristics and quality of functional and symbolic play in children with ASD. Many studies showed that children with ASD could not play, either functionally or symbolically, since neither was seen in the spontaneous play of these children (for a review, see Jarrold et al., 1993). Gould (1986), for example, suggested that children with ASD are not only delayed in the development of play but also that, once play develops, it is deviant compared to the play of children without ASD. Those who did show basic play, which tended to be stereotyped and manipulative, tended to be those children with normal verbal and nonverbal IQs, or those who were only mildly mentally retarded (Wing, Gould, Yeates, \& Brierley, 1977).

There has been some debate as to whether both functional play and symbolic play in children with ASD are impaired. Baron-Cohen (1987) and Lewis and Boucher (1988), for example, found that only symbolic play, and not functional play, was deficient in children with ASD. However, when these studies were re-examined using current 
definitions of symbolic play (e.g., Gould, 1986), as discussed above, children with ASD were found to demonstrate impairments in functional play as well. Other more recent studies have found an almost complete lack of both functional and symbolic play in ASD (Stahmer, 1995). Sigman and Ungerer (1984b) showed that doll play was particularly impaired in children with ASD. However, most of these studies have employed very small samples of children. Without systematic research examining specific aspects of play in larger samples of children with ASD, this debate is unlikely to be resolved.

Increasingly, recent studies have focused on whether or not children with ASD can play, i.e., elicited play, and not whether they do play, i.e., spontaneous play. The focus appears to have changed from spontaneous to elicited play as researchers become more interested in differentiating between competence and performance. Several researchers have found that in structured situations with prompts, children with ASD can play at the same level as appropriately matched controls, both functionally and symbolically (Gould, 1986; Lewis \& Boucher, 1988; Whyte \& Owens, 1989; Jarrold et al., 1993; Stahmer, 1995). The discrepancy between the ability to create and manipulate play symbols and the spontaneous production and use of play symbols parallels the dissociation between the two major components of language in children with ASD: understanding and production.

Stahmer (1995) has proposed that the lack of spontaneous play shown by children with ASD is due mainly to a lack of motivation; these children may simply find repetitive, manipulative play to be more rewarding. Stahmer (1995) supported this argument with evidence that, given sufficient motivation in the form of play opportunities or praise, children with ASD can be successfully trained to play symbolically. Similarly, 
Jarrold et al. (1993) suggested that a lack of motivation would help explain why children with ASD can play appropriately when the task is structured for them by others but show distinct deficits in spontaneous play.

Little is known about why children with ASD show deficits in spontaneous play. Some children with ASD can play spontaneously, some can learn to play, and some do neither (Stahmer, 1995). It may be that whether a child with ASD exhibits appropriate play behaviour depends on other areas of that child's development. Despite the triad of core deficits seen in all children with ASD, individual differences exist in the rate and quality of language development, as well as in social behaviours and nonverbal communication skills (Mundy, Sigman, Ungerer, \& Sherman, 1987). For example, children with ASD can be relatively high or low in terms of adaptive functioning, they can have very high or very low nonverbal cognitive abilities, they can be verbal or nonverbal, and they can be more or less socially impaired, while still showing the characteristic triad of features. This means that it is possible to obtain variability in a number of different functional domains within the same population of children. It is important to examine nonverbal cognitive ability, language ability, and social development for their relationship to symbolic play in order to understand the factors that may influence play. The evidence linking symbolic play to other cognitive domains, including cognitive ability, language ability, and social development is reviewed below. Cognitive Development and Symbolic Play

Normally developing infants, before they achieve a certain level of cognitive functioning, are unable to play either functionally or symbolically. Before the age of about eight months, children manipulate objects in a sensorimotor manner (Piaget, 1962). 
Their actions are said to be goal-oriented or for the purpose of learning about their environment, not merely for their own entertainment. By the time an infant enters the second year of life, he/she is able to functionally relate objects to each other in an increasingly complex manner. At twenty months of age, infants are able to begin to symbolically represent objects that are not present, or begin to make false attributions to objects. This further develops into sequential and finally social play as the child matures. Level of play is therefore dependent, at least partially, upon level of cognitive functioning.

The earliest studies conducted on symbolic play with children with ASD examined symbolic play in relation to cognitive development, especially nonverbal cognitive development. Many of these early studies matched children with ASD to controls on nonverbal cognitive ability (Jarrold et al., 1993). More recent support for the idea that cognitive functioning is related to play comes from a review by El'Konin (1999), who argued that play is very important in a child's cognitive development, especially as the child makes the transition from the concrete to the symbolic. He argued that, since changes in both play and cognitive development occur concurrently, they are likely related. Other researchers have found support for the idea that cognitive development is related to play ability. Gould (1986) found that scores on the Bayley Scales of Infant Development were positively correlated with ratings of play. Similarly, Baron-Cohen (1987) found that children with ASD who pretended during play had significantly higher nonverbal mental ages than those who did not.

In contrast to the studies discussed above, there is other evidence suggesting that nonverbal cognitive ability is not the best predictor of level of play in children with ASD. 
Nonverbal intelligence did not predict which children with ASD would benefit from play training in a study by Stahmer (1995). More direct evidence comes from studies that have matched children with ASD with children who are mentally retarded on nonverbal mental age. Riguet, Taylor, Benaroya, and Klein (1981) found that, even when compared to children with severe mental retardation, children with ASD have impaired play for their nonverbal mental ages. Power and Radcliffe (1989) also found that play in children with ASD was much more impaired than would be suggested by the children's nonverbal mental ages. Further, Wing et al., (1977) noted that children below a nonverbal mental age of twenty months do not show flexible symbolic play. They also found that even when children with mental retardation had nonverbal mental ages well above twenty months, if their verbal mental ages were below 20 months, they did not exhibit symbolic play. Therefore, while a deficit in nonverbal cognitive abilities may account for some of the play impairments seen in children with ASD, this may not be the only contributing factor to symbolic play deficits, as discussed below.

Verbal Development and Symbolic Play

The next area to consider is the verbal domain. Piaget specifically linked symbolic play and language development because he considered both to require symbolic representations. Piaget (1952) hypothesized that both play and language would increase in sophistication as the capacity for symbolic representation develops. Since Piaget, several researchers have found strong links between play and language.

Several possibilities have been proposed to explain why language and play are related. There are two in particular that stand out: the symbol deficit hypothesis (BaronCohen, 1987) and the metarepresentational hypothesis (Leslie, 1987). Both these 
hypotheses are based on the same assumption, namely that both play and language are symbol systems that arise from the same representational ability. According to the symbol deficit hypothesis, children with ASD are impaired in their ability to create and/or use symbols. More specifically, it is the ability to create representations of representations, or second-order representations, which is impaired in children with ASD, and not necessarily their ability to create first-order representations. Baron-Cohen (1987) cited as evidence the difficulties children with ASD experience with theory of mind. Theory of mind, or mentalizing, is a term used to describe the ability to predict relationships between external states of affairs and internal states of mind. Individuals with ASD are usually found to have an impaired theory of mind (for a complete description, see Frith, 2003). Mentalizing also involves the creation of these secondorder representations (for a complete description, see Baron-Cohen, 1987).

Similarly, Leslie (1987), also used theory of mind deficits to explain the difficulty children with ASD have in pretending something they know to be false lies. The difficulty was said to lie in their inability to decouple their knowledge about the world from their actions in a given situation. He termed this ability a capacity for metarepresentation. Again, this theory involves second-order thinking or "double knowledge," in which the child must know the true and pretend states of the world simultaneously. Both theories describe impairments in play as being related to an inability to understand this second-order knowledge.

Although there is some support for these hypotheses, a close examination of the literature makes such a simple explanation unlikely. The main finding that these hypotheses fail to explain is that in structured, prompted situations, children with ASD 
can in fact play symbolically (Gould, 1986; Jarrold et al., 1993; Lewis \& Boucher, 1988; Whyte \& Owens, 1989). If they truly had a deficit in symbol formation or metarepresentational ability, it should not be possible for symbolic play to be elicited from these children without significant training or modeling. It therefore appears that a deficit in second-order symbol formation cannot entirely explain the deficit in representational ability, either in play or linguistic form.

The first line of evidence supporting the relationship between language and play comes from observations of typical children. Spencer (1996) noted that in normally developing children, language and play emerged concurrently, and important developments in each skill emerged at similar points in the first two years of life. She found that the expression of single words arose at the same time that children were beginning to engage in simple representational play with realistic toys. Similarly, the use of word combinations emerged at almost the same time as the introduction of sequences of related play acts. Gould (1986) noted that symbolic play is first seen in the second year of life, and is closely tied to the development of language, especially of internalized language, which is equivalent to thought. She further observed that the developmental pace of language and play varies among individuals but followed the same pattern. Udwin and Yule (1982) reported that early concept formation and symbolization in play both preceded and developed alongside verbal language, and was a necessary precondition for language to develop. The close developmental association between the emergence of language and play suggests that the two are related in some manner.

Further evidence arises from studies testing the relationship between play and language through specific measurements of both play and language. Stahmer (1995) 
found that symbolic play was related to both vocabulary use and sentence complexity. Several other researchers have identified strong positive correlations between either receptive language and play (e.g., Lewis \& Boucher, 1988; Mundy et al., 1987; Musatti, Veneziano, \& Mayer, 1998; Spencer, 1996; Whyte \& Owens, 1989) or expressive language and play (e.g., Lewis \& Boucher, 1988; Mundy et al., 1987; Musatti et al., 1998; Spencer, 1996; Stahmer, 1995; Whyte \& Owens, 1989).

With respect to language and play in ASD, Baron-Cohen (1987) found that children with ASD who engaged in symbolic play had significantly higher verbal mental ages than did those who did not. Sigman and Ungerer (1984b) reported that while in normal and mentally retarded controls, only receptive language was related to play ability, both receptive language and expressive language were related to the play of children with ASD. They found strong correlations between language skills and play ratings. This suggested to these researchers that expressive language ability might be more important for the development of play than nonverbal cognitive ability (Power and Radcliffe, 1989).

As to temporal parameters of development, the relationship between language and play may be sequential rather than concurrent. Ungerer and Sigman (1984) investigated language and play development in normally developing full- and pre-term infants. They found that there were significant correlations between early play and later language development, suggesting that play skills might precede or be prerequisite to language development. Interestingly, in the Ungerer and Sigman (1984) study, early play skills were assessed at 13.5 months, an age prior to that at which symbolic play typically develops. This suggests that functional or relational play is also related to the creation 
and use of symbols. Wing et al. (1977) noted that there is no convincing evidence that a child without spontaneous symbolic play has acquired anything more than a limited vocabulary.

In contrast to the studies discussed above, some studies have failed to find support for the link between play and language development. Russell \& Russnaik (1981) found that play and language were unrelated in typically developing children, at least up to 22 months. They suggested that the two might be related later in life when verbal sociodramatic play develops. These researchers hypothesized that language may be a qualitatively different abstract level of symbolization than is play, and is less dependent upon sensorimotor skills. Fein (1981) reviewed several studies and reported that although certain developments in language and play appear concurrently, the relationship between the two is no longer apparent when age is partialled out. She stated that since development does not proceed evenly across different task domains in children with or without ASD, it is highly unlikely that the two would be found to correspond precisely. Most studies reviewed in Fein's paper did not convincingly show that language is either a precursor, concomitant, or resultant of play. Thus, there may be factors other than nonverbal cognitive ability and language that affect the development of symbolic play in children with ASD. The current study seeks to clarify the roles that receptive and expressive language might play in symbolic play in ASD in the context of other cognitive and social factors.

\section{Social Development and Symbolic Play}

ASD is a disorder that primarily affects social or affective development (APA, 1994; Fein, Pennington, Markowitz, Braverman, \& Waterhouse, 1986). In Kanner's 
original description of ASD (1943), he made the claim that individuals with ASD suffered from, first and foremost, an inability to form the appropriate social and affective relationships with other individuals. Recent studies (e.g., Klinger, Dawson, \& Renner, 2003) have suggested that social development may facilitate development in other domains, such as language or symbolic play. The current study seeks to extend the current research on symbolic play by testing the hypothesis that social development, at least for the ASD population, may contribute to symbolic play.

There is strong evidence for the influence of social deficits on symbolic play in ASD. Fein, Pennington, Markowitz, Braverman, and Waterhouse (1986) noted that "autistic aloofness" was the only inclusion criterion common across all studies of individuals with ASD; language deficits or stereotyped behaviours were secondary characteristics in many studies. These researchers noted that this aloofness was seen in all children with ASD, regardless of their cognitive profiles. They found that individuals with ASD had particular difficulties with tasks that involve social or affective stimuli, even if they could perform the same task efficiently with nonsocial stimuli. They also found that the areas of functioning that are typically impaired in individuals with ASD are those that are presumed to be most dependent upon social interactions for development, i.e., language and symbolic play. In contrast, those domains that are typically intact in individuals with ASD, such as visuospatial and sensorimotor processing are those that are least dependent upon social input and social context. Similarly, Whyte and Owens (1989) found that individuals with ASD seemed to have difficulty extracting meaning from social situations and events, as well as storing this information in a manner that allowed them to access it later. Based on similar findings, 
Dawson, Meltzoff, Osterling, \& Rinaldi (1998) concluded that individuals with ASD have a specific deficit in processing social stimuli. They further proposed that this deficit then leads to the other symptoms common to ASD, including symbolic play.

Symbolic play has been demonstrated to be associated with social development in a number of different studies. El'Konin (1999) argued that play is often socially oriented, a hypothesis that was supported by the observation that, through play, children re-enact their social and affective experiences (Göncü, Patt, \& Kouba, 2002). Play has been found to be very important in the development of social behaviours, as seen in both animal research (e.g., Vandenberg, 1978) and research with children (e.g., Wing et al., 1977). Fein (1981) also noted that play is related to social behaviour and functioning. She elaborated upon this by examining the relationship between popularity and play skills. She found that children who played functionally were less popular with their peers, and that symbolic play was associated with more positive patterns of peer interaction. Similarly, Wing et al. (1977) argued that play is important for the development of social behaviours in children with severe mental retardation. These researchers noted that a complete absence of symbolic play was closely linked to ASD or to simple stereotypies combined with poor social contact. Gould (1986) found that play age was significantly lower than language age in socially impaired children, but not in sociable children. Taken together, these findings suggest that level of competence in play may be dependent upon social interactions.

Further support for the link between social skills and play comes from research into the training of play skills in individuals with ASD. In the study by Stahmer (1995) cited earlier, an attempt was made to train children with ASD to play appropriately. She 
found that providing specific symbolic play training to children with ASD not only improved their symbolic play skills, but also improved their social interaction skills, as measured by the number of approaches to others and by the number of positive responses to approaches by others. By contrast, language training did not have a positive effect on social interaction. The children who were the best at interacting were also the children who engaged in the highest levels of symbolic play. Since interaction skills were not being targeted or taught in the play training, it could be concluded that symbolic skills are related to social interaction skills, and that training in these skills may allow some spillover to symbolic play skills and vice versa.

One factor that may explain this relationship between social skills and symbolic play attachment. In Fein et al.'s (1986) study of attachment in children with ASD, results pointed towards attachment as an explanation for the link between social factors and symbolic play. They found that language and symbolic play, both of which are heavily dependent upon social interest and social interaction, were highly correlated with attachment in these children. The children with ASD in their study who showed the most distress upon separation from their primary caregiver were the same children who had higher language and symbolic play scores. Sigman and Ungerer (1984a) found similar results: children with ASD who showed the strongest attachment relationships engaged in symbolic play, and used a doll as the agent of action, more frequently than did those children with weaker attachment relationships. They suggested two possibilities to explain their findings. The first was that children who have deep attachment relationships might develop symbolic skills more effectively than would those who were not as deeply attached (for a complete description of how this occurs, see Sigman \& 
Ungerer, 1984a). The second suggestion was that children with ASD who were able to form attachment relationships might not be as severely affected by ASD, and as such may have been able to capitalize more on the types of social interactions that are responsible for the development of a symbolic capacity. This may indicate that the attachment relationship provides social learning opportunities from which a child is expected to learn the skills necessary for symbolic representation.

Another plausible explanation for the relationship between social development and symbolic play arises from studies on theory of mind. As described above, both Leslie (1987) and Baron-Cohen (1987) have linked pretense with theory of mind. According to these researchers, as children start to understand pretense, they begin to understand that there can be different perspectives of a given situation, which then leads them to attribute these perspectives to other people.

Hobson $(1989,1990)$ also related a child's ability to mentalize with his/her symbolic play skills. Unlike Leslie (1987) and Baron-Cohen (1987), Hobson stated that symbolic play is dependent upon social development. His explanation was that infants learn about feelings through reciprocal interactions with significant adults. This helps them to perceive the orientations of others, and then to understand that multiple perspectives are possible, even to the same environmental stimulus. The ability to symbolize and to pretend then develops from this understanding. Hobson (1989) further explained that ASD appears to be related to an inability to share the experiences of others, which would then lead to impaired symbolic ability and theory of mind. He cited as evidence the fact that infants with ASD frequently show impaired joint attention. Joint attention refers to an interaction that involves the nonverbal sharing of experiences 
through mutual interest to an object or event, such as gaze following, pointing, and showing (Leekam \& Moore, 2001). Joint attention appears to be very important in the development of symbolic play. Mundy et al. (1987), for example, found that the children who were more likely to follow pointing by an adult also tended to show more symbolic play acts. This finding has more recently has been used to determine the diagnosis of ASD through the use of such tests as the Autism Diagnostic Observations Schedule (ADOS-WPS; Lord, Rutter, DiLavore, \& Risi, 1999). The results of Baron-Cohen, Leslie, and Frith (1985) support the hypothesis put forth by Hobson $(1989,1990)$ that stated that it is inability of individuals with ASD to share in the experiences of others that accounts for the impairments in symbolic play seen in ASD.

The relationship between language and play skills may also be explained by the social development of individuals with ASD. It is possible that social or affective contact leads to the development of both language and play skills in a predictable pattern. If social skills were not examined in this relationship, it would be easy to conclude that play skills are independently related to language skills. In a longitudinal study, Laasko, Poikkeus, Eklund, and Lyytinen (1999) found that early social skills predicted language ability several months later. Results of this type suggest that language, social skills, and play may share some common developmental pathway. Often, the function of language in play is social (Musatti et al., 1998), further consolidating the relationships between the three skills. Therefore, social development has potential as an important contributor to the development of symbolic play in children with ASD, but needs to be considered in relation to other skills such as language. 


\section{Methodological Considerations in the Study of Autism Spectrum Disorder}

Most previous studies examining play in children with ASD have suffered from methodological problems. These include studying only individuals with ASD from a limited range of abilities and employing a small sample size. As well, many studies examine the relation of only one or two areas of functioning to symbolic play, and so cannot examine the relative contributions of each to symbolic play.

Many studies have focused on relatively able individuals with ASD who are not representative of the entire spectrum of ASD. Conclusions drawn from these studies may only be applicable to these high functioning individuals and may not be generalizeable to children at the lower functioning end of the spectrum. The present study seeks to examine the issue of play development using a representative sample of children with ASD who came from different parts of a large province for assessment. The participants in this study composed a sample that was highly representative of the population in terms of level of functioning.

Sample size is also an issue in ASD research. Within the area of ASD, research is plagued by the difficulty of recruiting participants, especially given the relative rarity of the disorder within the general population. The current study relies on a large sample size. This is crucial since studies with small sample sizes, even samples of ten or fewer, are extremely common in ASD research (e.g., Baron-Cohen, 1987; Libby et al., 1998; Riguet et al., 1981). It is well known that small samples seriously limit not only the power of the study, but also the generalizeability of the results. The present study involves the examination of data for over 100 children with ASD collected over a period of ten years using the same instruments. 
Using these data, the aim of the study is to attempt to determine how play relates to other competences in children with ASD. While other studies have tried to examine how play relates either to nonverbal mental age, verbal abilities, or social skills, there is no study that has attempted to determine the relative importance of each of these factors to the development of play in the same group of children. This study uses a within group design to determine which features of children with ASD are linked to a higher competence in symbolic play.

This thesis is aimed at replicating, clarifying, and investigating the relations of autistic symptomatology, nonverbal cognitive ability, expressive and receptive language, and social development to symbolic play. Autistic symptomatology has not yet been related to symbolic play in previous studies. Based on previous research, nonverbal cognitive ability is related to symbolic play, but it cannot fully explain symbolic play in children with ASD. Language has also been related to symbolic play, but the relative contributions of receptive and expressive language are not known. Further, the relationship between social development and symbolic play in ASD has not yet been directly demonstrated in previous studies, nor have potential relations with other areas of cognitive functioning, such as language, been explored. The current study seeks to replicate earlier findings regarding nonverbal cognitive ability and language skills, while clarifying the relative contributions of expressive and receptive language. It also examines the relations of autistic symptomatology and social development to symbolic play. 


\section{Hypotheses}

Based on the above discussion, the following five hypotheses were proposed.

1. The severity of ASD symptomatology will be negatively correlated with the level of symbolic play competence, independently of chronological age. This hypothesis is suggested by the fact that impaired or lacking symbolic play is one of the associated symptoms of ASD (APA, 2000).

2. Nonverbal cognitive ability will be positively related to symbolic play abilities, based on the evidence that indicates a relationship between the two. This relationship will be independent of chronological age and autistic symptomatology.

3. Verbal ability, as measured through both receptive and expressive language, will be uniquely and positively related to symbolic play skills, above and beyond the influence of chronological age, autistic symptomatology, and nonverbal cognitive ability, based on the evidence that play is related to language skills. The present study seeks to explore the relative contributions of both receptive and expressive language to clarify the relationship between verbal ability and symbolic play.

4. The level of social development exhibited by children with ASD will be positively related to their symbolic play skills, independently from chronological age, autistic symptomatology, and other cognitive domains (nonverbal cognitive ability and language), based on the evidence that symbolic play is directly linked to social development, as cited above.

5. Due to the previously discussed view that both social development and verbal ability are related constructs, this relationship will be explored through a mediation analysis. Given that this is an exploratory hypothesis, no specific predictions are made. 
Method

\section{Participants}

The parents of all children who were seen for assessment at a major ASD clinic in Toronto, Canada between March 24, 1982 and January 8, 1992 were asked to give permission for the data collected for assessment purposes to be used for the purpose of research (see Appendix 1). The parents of all children consented to participation. Of these children, only those who were formally given a diagnosis of ASD were included in the present study.

The files of 130 eligible children were examined for completeness. Eight children were excluded from the study because the Lowe and Costello Symbolic Play Test had not been part of their assessments. A further 21 children were excluded because they had been rated as being untestable on the Symbolic Play Test. Children were rated as being untestable if their behaviour did not allow them to be evaluated using a given measure, or if their behaviour necessitated gross departures from standardized procedures. Examples of such behaviours include tantruming, disinterest, distractibility, or lack of understanding. The final sample was composed of 101 children, aged 24-216 months. The sample consisted of 86 boys and 15 girls, resulting in a ratio of approximately 1 girl to every 6 boys, which is reflective of the ASD ratio in the general population (Fombonne, 1999). Children represented a broad sample of the population of an entire Canadian province, although most came from the large metropolitan area in which the psychiatric teaching institute was located, with representation from all socioeconomic strata. For a complete description of the sample, see Konstantareas and Homatidis (1999). 


\section{Measures}

Symbolic Play. The Lowe and Costello Symbolic Play Test (SPT; Lowe \& Costello, 1976) was used to asses symbolic play and is a nonverbal measure of symbolic functioning in children aged 12-36 months. It is the only standardized test with norms for assessing play development. Children are systematically presented with four different sets of toys and are observed playing with them. It is important to note that all four scenarios involved human figures. The test was administered following standardized procedures. Play behaviours were recorded on a 24 -item checklist, each of which has very specific criteria that must be met in order for the behaviour to be recorded as present. The test does not require any expressive speech, and is therefore appropriate for use with children with ASD, many of whom have difficulty with verbal communication. Test scores increase predictably with age. The manual for the SPT notes that this is a reliable test (split half reliability $=.81$; test-retest reliability $=.75$ ), and can reliably predict concurrent and later language functioning, demonstrating its good psychometric properties. Scores from the SPT have also independently been shown to correlate significantly with ratings of the imaginativeness of play $(r=.40-.57$; Udwin \& Yule, 1982). Further, this test yields consistent results with both normal and handicapped children (Whyte \& Owens, 1989).

In this study, age equivalent play scores were used. As indicated earlier, if a child was rated as untestable on this test, he/she was removed from the study. Since norms for the SPT only provide age equivalents for raw scores of 5 (13 months) and over, and since several children obtained raw scores between 1 and 4 , it was necessary to develop a conversion system for these scores. According to Piaget (1962), infants in stage four of 
the sensorimotor period of development (those aged 8-12 months) start to apply known schemas to novel situations. They also begin to combine actions into sequences. The actions of infants become less goal directed and more mastery and enjoyment oriented. This, Piaget suggested, is the beginning of the development of play. Similarly, Vondra and Belsky (1991) stated that around nine to ten months, children begin to bring objects together to form meaningful relations, as seen in functional-relational play. Following this, children begin to introduce objects into their play in a meaningful manner. This suggests that, by around 9 months, children are beginning to develop the minimum skills necessary to achieve success on the SPT, the simplest items of which involve relating two common objects. A score of 1 was therefore assigned a play age of 9 months, a score of 2 a play age of 10 months, a score of 3 a play age of 11 months, and a score of 4 a play age of 12 months. This gradation was employed to allow for the analysis of a larger range of play scores.

Autistic Symptomatology. The Childhood Autism Rating Scale (CARS; Schopler, Reichler, DeVellis, \& Daly, 1980) was used to assess ASD symptomatology and was developed to objectively rate 15 different behaviours typical of children with ASD. Each of the behaviours is rated on a scale from 1 (normal) to 4 (severely abnormal). The scores are summed to provide a total score out of 60 . The scale has a clinical cutoff of 30, with scores of 37 and up indicating severe ASD. Higher scores indicate more severe symptomatology. Several studies have examined the reliability and validity of the CARS, each demonstrating its utility in assessing ASD symptoms. Estimates of internal consistency ranged from .73 (Garfin, McCallon, \& Cox, 1988) and .85 (Sturmey, Matson, \& Sevin, 1992) to .94 (Schopler et al., 1980). Similarly high interrater reliabilities have 
been reported in the literature (.71 or better; Schopler et al., 1980; Garfin et al., 1988). The CARS has been repeatedly shown to correlate highly with other ASD scales, such as the Real Life Rating Scale (Sevin, Matson, Coe, Fee, \& Sevin, 1991), the Diagnostic Assessment of the Severely Handicapped-II (Matson, Smiroldo, \& Hastings, 1998), and the Autism Diagnostic Interview Revised (Pilowsky, Yirmiya, Shulman, \& Dover, 1998), as well as clinicians' ratings (Schopler et al., 1980). This demonstrates its convergent validity. Several studies have attested to the ability of the CARS to discriminate between individuals with and without ASD with high success (e.g., Teal \& Wiebe, 1986; Eaves \& Milner, 1993). Matson et al. (1998) went so far as to claim that the CARS is the "gold standard for assessing autism" (p. 80).

For the current study, only clinicians' CARS ratings were used. For several of the children, more than one clinician independently completed the CARS in order to assess interrater reliability. In these cases (44\%), as agreement between raters was high ( $r=$ .93), an average of the two ratings was used.

Nonverbal Cognitive Ability. Three measures of nonverbal cognitive ability were employed in this study. The first is the Leiter International Performance Scale - Arthur Adaptation (Arthur, 1980). The scale involves a series of matching tasks in which children use blocks in an attempt to either match or construct patterns based on presented picture cues. All instructions are given without speaking, although encouraging statements were employed. The Leiter is designed to assess children aged 2 to 18 years, and yields a nonverbal mental age equivalent score. Scoring was done according to the Arthur Adaptation of the Leiter, as described in Arthur (1980). Scores can be converted into IQ scores by dividing the age equivalent in months by the child's chronological age 
in months and then multiplying by 100 . The Leiter was standardized on 289 American children, 48 of whom were re-examined three years later. Arthur (1980) reports that the Leiter, combined with the Point Scale of Performance Tests, provides adequate predictive validity of intelligence scores three years later.

Shah and Holmes (1985) suggested that as a measure of nonverbal intelligence, the Leiter is ideal for children with ASD as it requires no expressive or receptive language, very little social interaction, is not timed, is game-like, and does not take very long to administer. These authors reported good concurrent validity (correlations between WISC-R performance IQ and the Leiter equal to .82), and described previous research findings of adequate reliability. For the purpose of this study, nonverbal mental age equivalent scores were used.

The remaining two measures of nonverbal cognitive ability were Object Permanence and Operational Causality (adapted from Uzgiris \& Hunt, 1976). These measures were only included as measures of nonverbal cognitive ability if a child was not testable on the Leiter, as described below. The test of Object Permanence assesses knowledge of the constancy of objects when they are removed from sight. Children were first presented with an object of interest, which was then hidden beneath a screen. The child's behaviours were noted and compared with a scale adapted from Uzgiris and Hunt (1976). More screens were added, up to a total of three. The child's search behaviours can be taken as evidence for their belief that the object remained in existence despite being out of view, and the effectiveness of their searching demonstrates their cognitive maturity. The authors reported interrater agreements between $88 \%$ and $100 \%$ for this scale. The intersession stability ratings were also very high, and ranged from $73 \%$ to 
94\%. For the purpose of this study, if a child performed at ceiling (21-22 months), they were given a score of 22 months. If a child was untestable or performed at a level below the lowest level for this test (seven months), his/her score was considered to be missing. These ages were then taken as a measure of the child's nonverbal mental age.

The final measure examines Operational Causality. This is a measure of cause and effect knowledge in infants. The children were presented with a fire truck. The examiner unobtrusively turned on the siren by flicking a switch under the truck. The truck was again presented to the child. The siren was turned off, and the truck was given to the child to play with. The child's behaviours in attempting to turn the siren on were noted and taken as evidence of their knowledge of cause and effect, as well as of their cognitive development. Uzgiris and Hunt (1976) reported interrater agreements between $86 \%$ and $100 \%$, depending on the age of the child. They also reported high intersession stability, ranging from $55 \%$ to $86 \%$. For the purpose of this study, children who were untestable or performed below the lowest level for this test (five months), his/her score was considered to be missing. These ages were then taken as a measure of the child's nonverbal mental age.

If a child was deemed untestable on the Leiter, the Piagetian measure of Object Permanence was employed instead. If the child was untestable on both the Leiter and Object Permanence, his/her age equivalent from the Piagetian measure of Operational Causality was employed. If no scores could be obtained on any of the three measures of nonverbal mental age, the child's nonverbal cognitive ability score was considered to be missing. Both Object Permanence and Operational Causality were significantly correlated with the Leiter $\left(r_{s}=.697, p<.01\right.$ and $r_{s}=.674, p<.01$, respectively). 
Verbal Ability. Two aspects of verbal ability were examined in the present study: receptive language and expressive language. The Peabody Picture Vocabulary Test Revised (PPVT-R; Dunn \& Dunn, 1981) was used to assess receptive verbal ability. Subjects are shown a series of four pictures and asked to point to the one depicting a target word. The test does not require the subject to use spoken language. The PPVT-R was standardized on a sample of 4200 children who ranged from 2.5 to 18 years, as well as on a sample of adults. Split-half reliabilities for both Form $\mathrm{L}$ and $\mathrm{M}$ were similar, ranging from .61 to .88 , with the median reliabilities being .80 and .81 respectively. Immediate test-retest reliability of the raw scores ranged from .73 to .91 , with a median reliability of .82. A similarly high delayed test-retest reliability for raw scores, with a median reliability of .78. In terms of validity, the PPVT-R has good content validity and construct validity. The PPVT-R has been independently shown to correlate moderately with measures of verbal intelligence given four years later $(r \mathrm{~s}=.33-.49$; Silva, 1986). For this study, verbal mental age equivalent scores were used. If a child was rated as untestable, the child's score was considered to be missing.

The Reynell Developmental Language Scales (First Edition; RDLS; Reynell, 1977; Reynell \& Huntley, 1985) were used in the current study as a measure of both receptive language and expressive language. In ASD, this tool is frequently used to assess a child's expressive and receptive language abilities. It is comprised of two scales: an Expressive language scale that examines language structure, vocabulary, and language content; and a Verbal Comprehension (or Receptive language) scale that looks at concept formation and understanding. Both scales were employed in this study. The test manual reported that the RDLS is reliable (average split-half reliabilities: expressive $=.91$, 
receptive $=.83$ ) and has adequate content, concurrent, and predictive validities. An independent assessment of the instrument has shown that test-retest reliability was .43 for the expressive scale and .52 for the receptive scale (Silva, 1986). For this study, verbal mental age equivalent scores were used. If a child was rated as untestable on this measure, his/her score was considered to be missing.

Social Development. The Developmental Profile II (Alpern, Boll, \& Shearer, 1980) taps a child's development across five domains, each of which is translated into a developmental age equivalent: Physical, Self-Help, Social, Academic, and Communication. On the social subscale, parents are asked by a clinician to rate whether their child can or does perform a series of 36 items at least $50 \%$ of the time. A total score on this scale is then computed and converted into an age equivalent. Alpern, Boll, and Shearer (1980) standardized the Developmental Profile II on a sample of 3008 children aged from birth through twelve years. Based on the standardization sample, they concluded that each of the five scales of the Developmental Profile II provide a highly valid assessment of development. They also found that mothers could report very accurately on their children's development. In terms of reliability, Alpern, Boll, and Shearer (1980) reported extremely high scorer, reporter, and test-retest reliability. In addition to interviewing the parents on the child's functioning levels, reliability data were collected by using two close to ceiling items. If the parental reports were below or above the child's observed ability, the child's teacher was contacted to provide additional information on the relevant scale. For the purposes of this study, only the Social development scale was employed. 


\section{Procedure}

All data were collected as part of the assessment process. Tests were administered following standardized procedures. Often, however, minor departures from standardization were necessary to elicit responses from the participants. Since it is well documented that individuals with ASD use speech and gestures more frequently when specifically prompted (Gould 1986), this seemed reasonable and necessary. As such, when two scores were provided for the same measure by two clinicians in the file, one with strict criteria and a second with more lenient criteria or prompting, the second score was used to give the child the full benefit of his/her ability. Participants' case files were systematically reviewed, and data were extracted from assessment reports and case notes, as well as from original protocols, where available. In the case of contradictory information, one of the original clinicians involved in the assessment was consulted for clarification. For children who had undergone a reassessment a year later, the second assessment was used to maximize the number of children who were testable on the measures.

\section{Results}

Descriptive statistics (frequencies, means, and standard deviations) were calculated for chronological age, play age, nonverbal mental age, receptive single-word vocabulary age, expressive language age, receptive language age, social development age, and CARS scores. These are presented in Table 1. An SPSS-10 package was employed for all analyses. The intercorrelation matrix for all these variables is presented in Table 2. 
Table 1

Descriptives for Chronological Age, Symbolic Play Age, Autistic Symptomatology, Nonverbal Cognitive Ability, Expressive Language, Receptive Language, Receptive Single-word Vocabulary, and Social Development.

\begin{tabular}{lccc} 
Measure & $N$ & $M$ & $S D$ \\
\hline Chronological Age & 101 & 91 & 43 \\
Symbolic Play Age & 101 & 22 & 10 \\
Autistic Symptomatology & 86 & 39 & 7 \\
Nonverbal Cognitive Ability & 89 & 47 & 37 \\
$\begin{array}{l}\text { Verbal Ability } \\
\text { Expressive Language }\end{array}$ & 69 & 34 & 20 \\
$\quad$ Receptive Language & 65 & 34 & 14 \\
$\quad \begin{array}{l}\text { Receptive Single-word } \\
\text { Vocabulary }\end{array}$ & 57 & 46 & 27 \\
Social Development & 100 & 35 & 18 \\
\hline
\end{tabular}

Note. The above age equivalent scores for symbolic play, nonverbal cognitive ability, verbal ability, and social development are all reported in months. Autistic symptomatology scores can range from 15 to 60; a score of 30 represents the clinical cutoff for Autistic Disorder, with higher scores representing more severe symptomatology. 
Table 2

Intercorrelation Matrix of Key Independent Variables for Total Sample.

\begin{tabular}{|c|c|c|c|c|c|c|c|}
\hline $\begin{array}{l}\text { Measures } \\
\text { 1. Chronological } \\
\text { Age }\end{array}$ & $\begin{array}{l}2 \\
.19 \\
(101)\end{array}$ & $\begin{array}{l}3 \\
.52 \\
(89)\end{array}$ & $\begin{array}{l}4 \\
.39 \\
(57)\end{array}$ & $\begin{array}{l}5 \\
.22 \\
(69)\end{array}$ & $\begin{array}{l}6 \\
.36 \\
(65)\end{array}$ & $\begin{array}{l}7 \\
.34 \\
(100)\end{array}$ & $\begin{array}{l}8 \\
-.05 \\
(86)\end{array}$ \\
\hline $\begin{array}{l}\text { 2. Symbolic Play } \\
\text { Age }\end{array}$ & & $\begin{array}{l}.73 \\
(89)\end{array}$ & $\begin{array}{l}.44 \\
(57)\end{array}$ & $\begin{array}{l}.63 \\
(69)\end{array}$ & $\begin{array}{l}.64 \\
(65)\end{array}$ & $\begin{array}{l}.69 \\
(100)\end{array}$ & $\begin{array}{l}-.54 \\
(86)\end{array}$ \\
\hline $\begin{array}{l}\text { 3. Nonverbal } \\
\text { Cognitive Ability }\end{array}$ & & & $\begin{array}{l}.67 \\
(51)\end{array}$ & $\begin{array}{l}.64 \\
(63)\end{array}$ & $\begin{array}{l}.77 \\
(59)\end{array}$ & $\begin{array}{l}.78 \\
(88)\end{array}$ & $\begin{array}{l}-.49 \\
(80)\end{array}$ \\
\hline $\begin{array}{l}\text { 4. Receptive Single } \\
\text { Word Vocabulary }\end{array}$ & & & & $\begin{array}{l}.79 \\
(55)\end{array}$ & $\begin{array}{l}.85 \\
(55)\end{array}$ & $\begin{array}{l}.66 \\
(57)\end{array}$ & $\begin{array}{l}-.54 \\
(48)\end{array}$ \\
\hline $\begin{array}{l}\text { 5. Expressive } \\
\text { Language }\end{array}$ & & & & & $\begin{array}{l}.88 \\
(62)\end{array}$ & $\begin{array}{l}.72 \\
(68)\end{array}$ & $\begin{array}{l}-.55 \\
(60)\end{array}$ \\
\hline $\begin{array}{l}\text { 6. Receptive } \\
\text { Language }\end{array}$ & & & & & & $\begin{array}{l}.83 \\
(64)\end{array}$ & $\begin{array}{l}-.56 \\
(57)\end{array}$ \\
\hline $\begin{array}{l}\text { 7. Social } \\
\text { Development }\end{array}$ & & & & & & & $\begin{array}{l}-.54 \\
(85)\end{array}$ \\
\hline $\begin{array}{l}\text { 8. Autistic } \\
\text { Symptomatology } \\
\text { (CARS) }\end{array}$ & & & & & & & \\
\hline
\end{tabular}

Note. All scores except for Autistic Symptomatology are presented after a logarithmic (base 10) transformation of months to correct for non-normal samples.

All correlations above .30 are significant at the $p<.01$ level. Correlations below .30 are nonsignificant, $p>.05$. 


\section{Preliminary Analyses}

A preliminary exploration of the data revealed that the clinicians' ratings of autistic symptomatology were normally distributed. None of the age variables, chronological age, symbolic play, nonverbal cognitive ability, receptive single-word vocabulary age, receptive language, expressive language, and social development, however, approximated normality. Most were significantly positively skewed. As such, all age variables were transformed using a base 10 logarithmic transformation. Following this, receptive single-word vocabulary and receptive language were standardized and summed to create one receptive language score. Re-examination of the data after the transformation showed that this transformation corrected the positive skew, and caused all the age variables to approach or meet normality according to the Kolmogorov-Smirnov test of normality. An approximation of normality and homogeneity of variance are both necessary conditions for correlation and regression analyses. All other assumptions upon which these tests are based were understood to be met due to the normality of the data.

\section{Predictors of Symbolic Play}

Hypothesis 1, that clinicians' ratings of autistic symptomatology would be negatively related to children's symbolic play ages, was tested using a hierarchical multiple regression analysis. Chronological age was entered in the first block (model 1) and autistic symptomatology was entered in the second (model 2), both predicting age equivalent scores from the symbolic play test. The results of this analysis are presented in Table 3. The results indicated that, even after controlling for chronological age, autistic symptomatology was significantly associated with symbolic play in all children 
Table 3

Hierarchical Regression Analysis with Autistic Symptomatology Predicting Symbolic Play Development

\begin{tabular}{lcrll} 
Variables & $\Delta R^{2}$ & $F$ change & $\beta$ & $r$ \\
\hline \multicolumn{5}{c}{ Symbolic Play Development } \\
Step 1. Chronological Age & .06 & $5.27^{*}$ & $.24 *$ & .19 \\
Step 2. Autistic Symptomatology & .28 & $35.45^{* * *}$ & $-.53^{* * * *}$ & $-.54^{* * *}$ \\
\hline$* p<.05 \quad * * p<.01 \quad * * * p<.001$
\end{tabular}


with $\operatorname{ASD}(F$ change $(1,83)=35.45, p<.001)$. Autistic symptomatology uniquely explained $28 \%$ of variance in symbolic play, while age accounted for less that $1 \%$ of it. Hypothesis 2 , that nonverbal cognitive ability would be positively related to symbolic play, was also examined with a hierarchical multiple regression analysis. Chronological age and autistic symptomatology were entered into the first step (model 1), with nonverbal cognitive ability in the second (model 2), both predicting symbolic play age. The results, presented in Table 4, indicated that nonverbal cognitive ability significantly predicted symbolic play age, even after controlling for chronological age and autistic symptomatology $(F$ change $(1,76)=55.38, p<.001)$. Nonverbal cognitive ability uniquely accounted for an additional $28 \%$ of the variance in symbolic play after considering chronological age and autistic symptomatology.

Hypothesis 3 stated that verbal abilities overall would be positively related to symbolic play age, and addressed the relative contributions of receptive versus expressive language to symbolic play. This hypothesis was tested with two hierarchical multiple regression analysis, one examining receptive language and the other examining expressive language. The first analysis consisted of chronological age, autistic symptomatology, and nonverbal cognitive ability as predictor variables, all of which were entered in the first block (model 1) and the receptive language composite entered in the second block (model 2), all predicting symbolic play. The results of this analysis, presented in Table 5, indicated that receptive language does not contribute significantly to symbolic play above and beyond the contributions of chronological age, autistic symptomatology, and nonverbal cognitive ability $(F$ change $(1,39)=0.61, p>.05)$. 
Table 4

Hierarchical Regression Analysis with Nonverbal Cognitive Ability Predicting Symbolic Play Development

\begin{tabular}{lllll} 
Variables & $\Delta R^{2}$ & $F$ change & $\beta$ & $r$ \\
\hline & \multicolumn{3}{c}{ Symbolic Play Development } \\
& & & & \\
Step 1. Chronological Age & .34 & $19.53^{* * *}$ & $.21^{*}$ & .19 \\
$\quad$ Autistic Symptomatology & & & $-.52^{* * *}$ & $-.54^{* * *}$ \\
Step 2. Nonverbal Cognitive Ability & .28 & $55.38^{* * *}$ & $.73^{* * * *}$ & $.73^{* * *}$ \\
\hline
\end{tabular}

$* p<.05 \quad * * p<.01 \quad * * * p<.001$ 
Table 5

Hierarchical Regression Analysis with Receptive Language Predicting Symbolic Play Development

\begin{tabular}{lllll} 
Variables & $\Delta R^{2}$ & $F$ change & $\beta$ & $r$ \\
\hline & \multicolumn{3}{c}{ Symbolic Play Development } \\
& & & & \\
Step 1. Chronological Age & .49 & $12.91^{* * *}$ & $-.32^{*}$ & .19 \\
Autistic Symptomatology & & & -.27 & $-.54^{* * *}$ \\
Nonverbal Cognitive Ability & & & $.62^{* * *}$ & $.73^{* * *}$ \\
Step 2. Receptive Language & .01 & 0.61 & .16 & $.53^{* * *}$ \\
\hline
\end{tabular}

$* p<.05 \quad * * p<.01 \quad * * * p<.001$ 
The second analysis examining the relation between verbal ability and symbolic play tested whether expressive language was related to symbolic play. Chronological age, autistic symptomatology, and nonverbal cognitive ability were entered into the first block (model 1), with expressive language entered into the second block. The results, presented in Table 6 , showed that expressive language was significantly related to symbolic play $(F$ change $(1,52)=8.72, p<.01)$. Expressive language uniquely explained $5 \%$ of the variance in symbolic play, above that explained by the other variables.

A further hierarchical multiple regression analysis was conducted to verify that these results were not artifacts of the fact that the effects of expressive and receptive language were tested with separate analyses. The first step involved entering chronological age, autistic symptomatology, and nonverbal cognitive ability (model 1), and the second both expressive and receptive language (model 2). The results indicated that only expressive, not receptive, language was a significant predictor of symbolic play (expressive language: $\beta=0.484, t(37)=2.28, p<.05$; receptive language: $\beta=-0.03, t$ $(37)=-1.51, p>.05)$. This result is consistent with the aforementioned results regarding expressive and receptive language, and suggest that only expressive language, and not receptive language, is significantly related to symbolic play above and beyond the effects of chronological age, autistic symptomatology, and nonverbal cognitive ability.

Turning to social development, hypothesis 4 predicted that symbolic play would be positively related to social development. This hypothesis was again tested using a hierarchical multiple regression analysis. Step 1 involved entering chronological age, autistic symptomatology, nonverbal cognitive ability, and expressive language (model 1). Model 2 included social development as a predictor of symbolic play. The results are 
Table 6

Hierarchical Regression Analysis with Expressive Language Predicting Symbolic Play Development

\begin{tabular}{|c|c|c|c|c|}
\hline Variables & $\Delta R^{2}$ & $F$ change & $\beta$ & $r$ \\
\hline & \multicolumn{4}{|c|}{ Symbolic Play Development } \\
\hline $\begin{array}{l}\text { Step 1. Chronological Age } \\
\text { Autistic Symptomatology } \\
\text { Nonverbal Cognitive Ability }\end{array}$ & .63 & $29.56 * * *$ & $\begin{array}{l}-.36^{* * *} \\
-.18 \\
.75^{* * *}\end{array}$ & $\begin{array}{l}.19 \\
-.54^{* * * *} \\
.73^{* * *}\end{array}$ \\
\hline Step 2. Expressive Language Age & .05 & $8.72 * *$ & $-.34 * *$ & $.63 * * *$ \\
\hline
\end{tabular}


summarized in Table 7. Analyses indicated that social development did not uniquely account for variance in symbolic play for the entire sample $(F$ change $(1,50)=1.08, p>$ $.05)$. Closer examination of the data on the relationship between social development and symbolic play appeared to be moderated by nonverbal IQ, defined as nonverbal mental age divided by chronological age and multiplied by 100 . The data were therefore split into high and low functioning groups using a median split of IQ scores. When controlling for chronological age, autistic symptomatology, nonverbal cognitive ability, and expressive language, the relationship between social development age and play age was significant, but only for those children with higher nonverbal cognitive ability, i.e., those who achieved IQ scores above the median $(r=.43, p<.05$; see Figure 1$)$, and not for those children with lower nonverbal cognitive ability, i.e., those who achieved IQ scores below the median $(r=-.25, p>.05$; see Figure 2$)$.

The final analysis is related to the exploration of the relationship between social development and verbal ability as related to the prediction of symbolic play. This relationship was examined using the mediational approach put forth by Baron and Kenny (1986). Based on previous research, expressive language was tested as a mediator of the relationship between social development and symbolic play. Following the criteria specified by Baron and Kenny (1986), the first step was to show that there is a relationship between social development and symbolic play. Social development is a significant predictor of symbolic play $(\beta=.69, t(98)=9.45, p<.001)$. The second step was to regress expressive language on social development. The results indicated that social development was a significant predictor of expressive language $(\beta=.72, t(66)=$ $8.41, p<.001)$. The final step was to regress symbolic play on both expressive language 
Table 7

Hierarchical Regression Analysis with Social Development Predicting Symbolic Play Development

\begin{tabular}{lllll} 
Variables & $\Delta R^{2}$ & $F$ change & $\beta$ & $r$ \\
\hline & \multicolumn{3}{l}{ Symbolic Play Development } \\
& & & \\
& & & \\
Step 1. Chronological Age & .68 & $27.20^{* * *}$ & $-.37^{* * *}$ & .19 \\
$\quad \begin{array}{lll}\text { Autistic Symptomatology } \\
\text { Nonverbal Cognitive Ability }\end{array}$ & & & -.04 & $-.54^{* * *}$ \\
$\quad \begin{array}{llll}\text { Expressive Language } \\
\text { Step 2. Social Development }\end{array}$ & & & $.59^{* * *}$ & $.73^{* * *}$ \\
& & & $.34^{* *}$ & $.63^{* * *}$ \\
\end{tabular}

$* p<.05 \quad * * p<.01 \quad * * * p<.001$ 


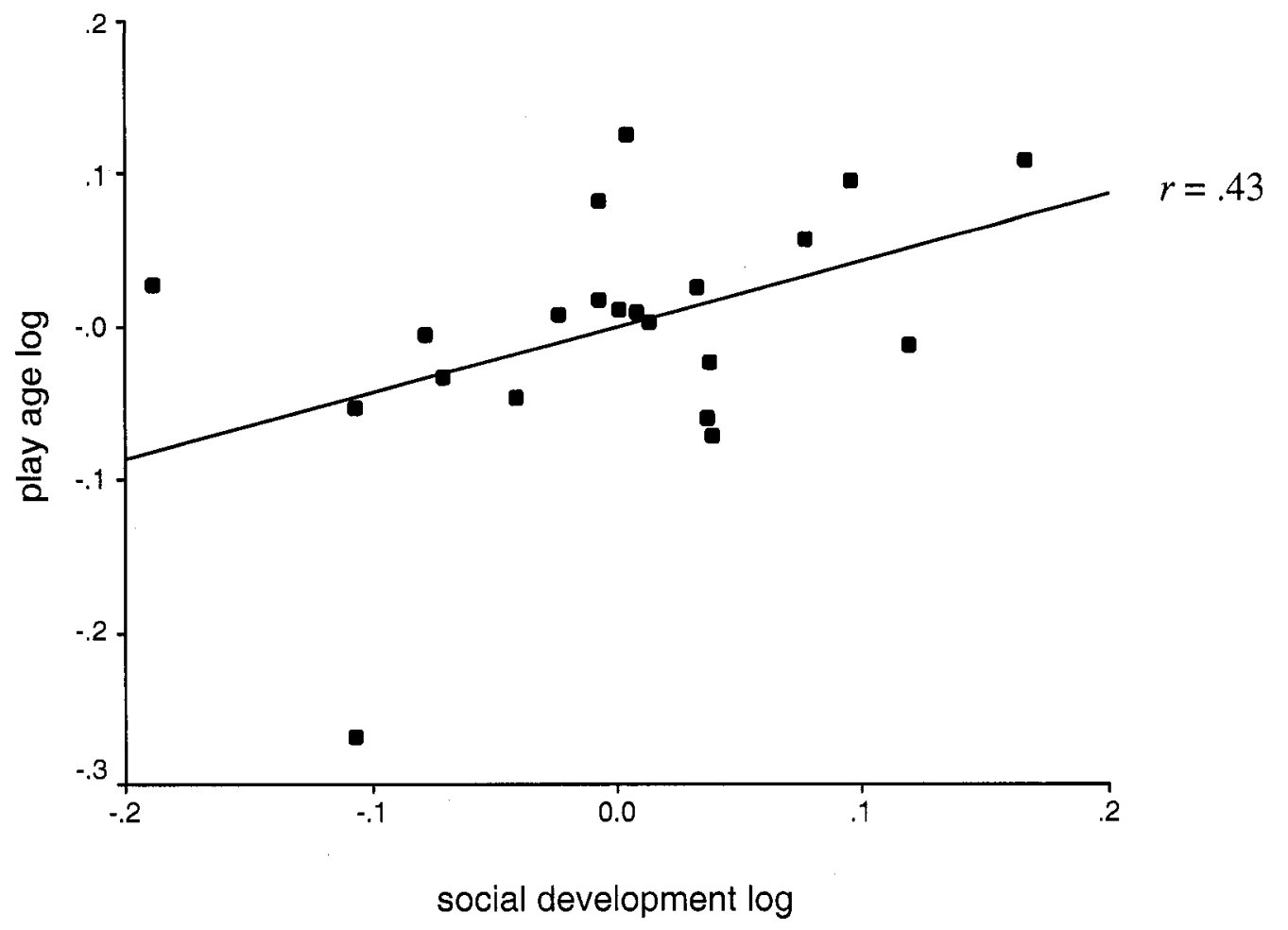

Figure 1. Scatterplot showing the relationship between Play Age Log and Social Development Age Log for High IQ children with ASD. 


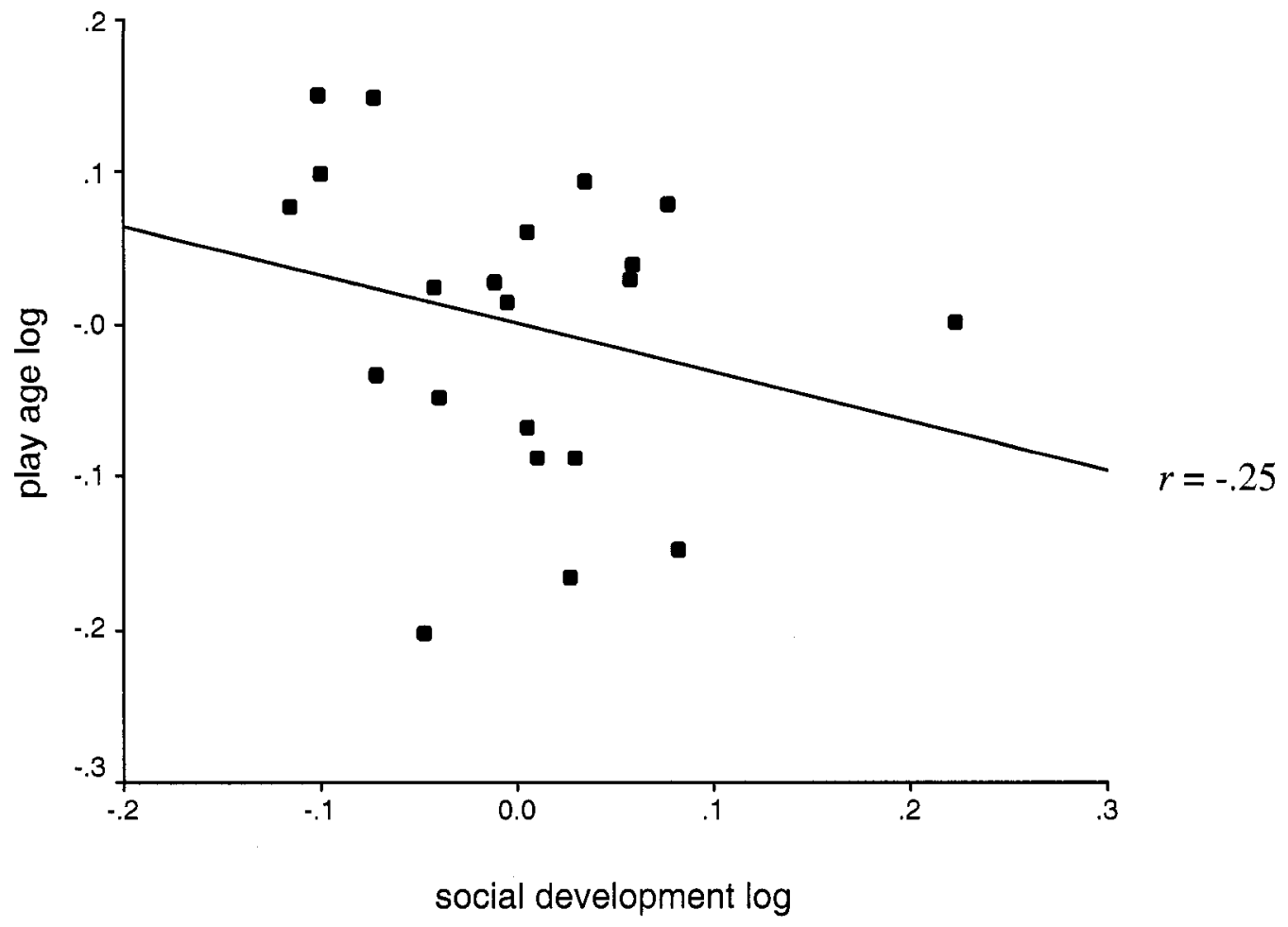

Figure 2. Scatterplot showing the relationship between Play Age Log and Social Development Age Log for Low IQ children with ASD. 
and social development in order to test the effect of including the mediator predictive ability of social development. The relationship between social development and symbolic play was still significant, but weakened, with the inclusion of the mediator ( $\beta=$ $.37, t(65)=2.87, p<.01)$. Using the Sobel test, the decrease in the regression coefficient was significant $(z=2.65, p<.01)$. This indicates that expressive language acts as a partial mediator of the relationship between social development and symbolic play. The results of this analysis are shown in Figure 3.

\section{Discussion}

The present study aimed to explore the association between symbolic play and a variety of other developmental domains, including nonverbal cognitive ability, verbal ability, symptom severity, and social development. Previous studies have shown that although nonverbal cognitive ability and verbal skills are positively related to symbolic play, the deficit in symbolic play seen in children with ASD often exceeds that predicted by these abilities (Power \& Radcliffe, 1989; Riguet et al., 1981). The purpose of this study was to clarify the relationship between symbolic play and autistic symptomatology, nonverbal cognitive ability, receptive and expressive language, and social development. This study is unique in that it employed a large, representative sample of children with ASD. The design employed was within-groups, allowing comparisons between developmental domains within the same population of children. While previous studies have examined the relationship between symbolic play and one of cognitive ability, verbal ability, or social development, this study is one of the first to examine the influences of several factors on symbolic play within the same group of children. 


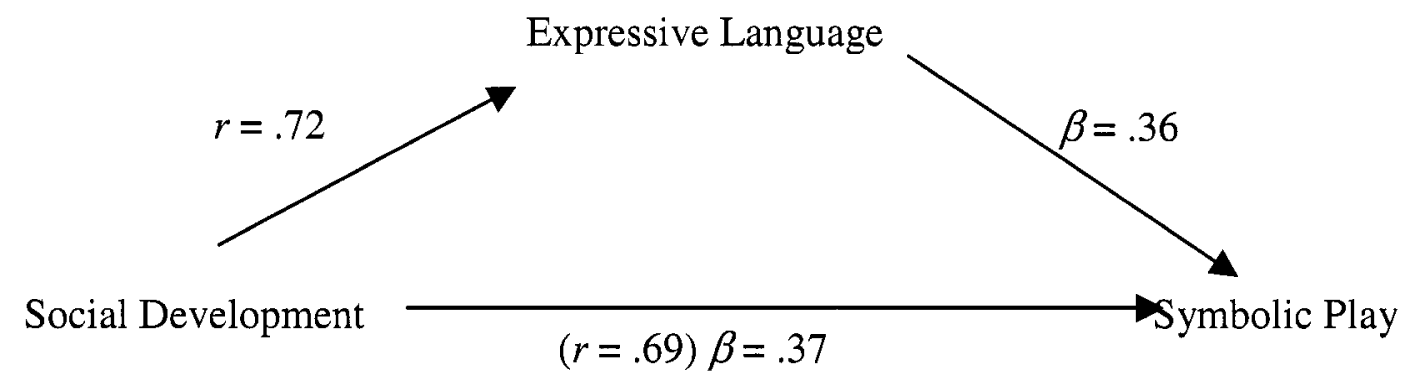

Figure 3. Expressive language as the mediator of the relationship between social development and symbolic play. All correlations are significant at the .001 level. 
Autistic Symptomatology and Symbolic Play

As predicted, the relationship between autistic symptomatology and symbolic play was significant and negative, even after controlling for the effects of chronological age. This means that the more severe a child's symptomology, as rated by a clinician, the lower the level of symbolic play. This is consistent with expectations, as impaired symbolic play is a recognized symptom of ASD according to the DSM-IV-TR (APA, 2000). This finding suggests that absent or impaired symbolic play can be used as a valid symptom of ASD.

Nonverbal Cognitive Ability and Symbolic Play

In examining the relationship between nonverbal cognitive ability and symbolic play age, it was found that the two were significantly positively correlated, even after controlling for chronological age and autistic symptomatology. This indicates that the more cognitively impaired an individual was, the more impaired his/her play abilities were. The very strong relationship shown in this study is consistent with both clinical knowledge and previous findings that cognitive ability is related to play skills (BaronCohen, 1987; Gould, 1986). Although most previous studies have found that this relationship exists, they also showed that the play deficit seen in children with ASD goes beyond what might be predicted by the children's nonverbal cognitive ability (Power \& Radcliffe, 1989; Riguet et al., 1981). It was therefore felt that it was useful to explore any possible additional relationships. Although nonverbal cognitive ability was a strong predictor of symbolic play in the present study, it appeared that, even when controlling for nonverbal cognitive ability, other factors such as language ability and social 
development play a significant role in determining symbolic play ability. These relationships are discussed next.

Language Ability and Symbolic Play

In this study, only expressive language, and not receptive language, was found to relate to play age. The finding that higher expressive language ability is associated with better developed symbolic play skills is consistent with existing evidence in this area, as several researchers have found expressive language to be related to symbolic play in children with ASD (e.g., Ungerer \& Sigman, 1984; Whyte \& Owens, 1989) and also in children who are deaf (Spencer, 1996). It may be that it is often through expressive language that a child communicates that he/she is playing, especially symbolically. Musatti et al. (1998) outlined several ways in which play is enhanced by expressive language, such as organizing activities, communicating intent, and creating symbolic meanings. All of these functions are related to expressive language. As well, from the measurement standpoint, the verbal concomitants of play render it easier for adults to feel secure in their judgments that the children are in fact engaged in symbolic play when they verbalize their play activities.

The finding that receptive language was not significantly related to symbolic play after controlling for the other variables was not expected on the basis of existing literature. Several researchers have found that receptive vocabulary is related to symbolic play (Lewis \& Boucher, 1988; Mundy et al., 1987; Riguet et al., 1981; Sigman \& Ungerer, 1984b; Whyte \& Owens, 1989). One possibility that might account for this difference is the relative abilities of the children participating in this study. As indicated earlier, most studies have employed only higher functioning individuals with ASD, while 
this study tested a representative clinical sample, incorporating children with a wide range of abilities. It may be that receptive language and receptive vocabulary contribute to play independently only in so far as to allow children to make use of the suggestions of other people. Children with ASD are likely to treat others as nonexistent (Frith, 2003), and may be less likely to take notice of their suggestions and subsequently incorporate them into play. However, there is evidence that children with ASD can be taught to play symbolically (e.g., Stahmer, 1995), which indicates that these children can make use of suggestions when specifically instructed; they just may not do so unless they are given a direct command. Many previous studies have employed higher functioning individuals with ASD as subjects. These individuals would presumably have been less impaired, both socially and otherwise, than would the current sample that was composed of individuals with a wide range of ability; they therefore may have been more willing or able to take into account the suggestions of others. This may account for the finding in previous research that symbolic play was related to receptive language.

Alternately, the definition of symbolic play in this study differed from that used in other studies, that have followed Baron-Cohen's (1987) definition of symbolic play. Following the strict definition of symbolic play, fewer children with ASD actually engage in what some define as symbolic play, resulting in only the higher functioning individuals with ASD showing symbolic play. The present study used a more lenient definition of symbolic play, which allowed for a wider range of children with ASD to be considered as demonstrating play abilities. This may account for the difference in findings between this and previous studies. 
Aside from methodological considerations, however, the results may genuinely relate to the low relevance of receptive language for symbolic play. Considering the large $\mathrm{N}$ in the present study, it may be appropriate to conclude that symbolic play is more strongly related to the generative rather than the interpretive function of language. Jarrold et al. (1993) suggested that the impairment in symbolic play seen in children with ASD might be related to a difficulty in generating play ideas, a hypothesis that is supported by the present findings. Both symbolic play and expressive language require the child to generate or produce words or actions independently, while receptive language merely requires the child to passively process what is being said. As indicated in the introduction, Jarrold et al. (1993) cited research from several different domains, including memory, word fluency, and drawing, that supports the idea that children with ASD have difficulty generating representations that are not prompted by cues. This possibility allows for the finding that children with ASD, if prompted, can play symbolically even though they do not do so spontaneously (Gould, 1986; Jarrold et al., 1993; Lewis \& Boucher, 1988; Stahmer, 1995; Whyte \& Owens, 1989), something the symbol deficit hypothesis does not allow. Additional systematic research focusing on the different aspects of language will be needed to examine why expressive language but not receptive language is related to symbolic play.

Social Development and Symbolic Play

Contrary to predictions, social development was not related to symbolic play for the entire sample of children with ASD. Further exploration indicated that nonverbal cognitive ability appeared to be acting as a moderator of the relationship between social development and play ability. For children with ASD who had nonverbal IQ scores 
above the sample median, social development was highly positively related to symbolic play ability. This relationship was negative and did not approach significance for those children with IQ scores below the sample median. It is important to note that for this sample, the median IQ was 66 , just below the clinical cutoff for mental retardation, or an IQ of 70. This suggests that comorbid mental retardation may act as a moderating factor in the relationship between symbolic play and social development.

The finding that high functioning children with ASD may be qualitatively different from their lower functioning counterparts parallels findings from other research in unrelated domains. For example, Konstantareas, Zajdeman, Homatidis, and McCabe (1988) found that maternal speech patterns differed for high and low functioning children with ASD. Similarly, it has been found that the age of onset of ear infections is early in low functioning children with ASD when compared with their high functioning peers (Konstantareas \& Homatidis, 1987). As well, it has to be noted that the higher functioning children may be more likely to also have better expressive language skills, which may be responsible for the effects obtained that favors the higher functioning subgroup of children. The current findings provide further evidence that high and low functioning children with ASD are different from each other.

In addition, this finding provides further support for the relationship of social skills and symbolic play in ASD. Many studies, in investigating ASD, select a sample of children who are high functioning, in or near the average range of cognitive ability, so as to examine the effects of ASD independently from those of mental retardation. In the current subsample of children with ASD with higher nonverbal cognitive ability, those who had better-developed social skills also had more highly developed symbolic play 
abilities. Amongst those children with lower nonverbal cognitive ability there was no significant relationship between social development and symbolic play. This suggests that cognitive impairment may be impacting the symbolic play performance of children with ASD. In fact, as indicated earlier, nonverbal cognitive ability was a very strong predictor of symbolic play in this study. Within the subsample of relatively able children with ASD, the relationship between social development and symbolic play was significant.

This finding is in accord with a number of theoretical positions, one of which is Hobson's work on theory of mind $(1989,1990)$. Hobson suggested that children with ASD are impaired in their ability to understand emotions, and thus cannot benefit from the reciprocal interactions that occur between infant and caregiver. Children with ASD therefore do not learn about emotions and different perspectives, and never learn that other individuals can believe different things than they themselves do. This, according to Hobson, then leads to impaired pretense and, later, impaired theory of mind.

Wellman (1993) put forth another possible hypothesis that links social development and symbolic play. According to his proposition, normally developing infants orient themselves selectively to other people within a few months of birth. $\mathrm{He}$ argued that infants are biologically programmed to identify and attend to humans, as well as to differentiate between human and mechanical causation. By the end of the first year of life, most infants are able to understand that looking at, seeking to obtain, or emotionally reacting to an object communicates a degree of intention inherent in human actions and experiences. This contributes to the infants' understanding of people as agents with unique perspectives and orientations towards the world. Wellman went on to 
describe a third stage that emerges in toddlerhood, which is that of pretense. In order to pretend, a child needs to understand that multiple perspectives can be held towards the same object or event, and then be able to manipulate his/her own beliefs to satisfy the demands of the pretend situation, similar to Hobson's $(1989,1990)$ proposition. By the time children reach three years, there is considerable evidence that they are able to understand that people have beliefs, desires, and emotional reactions that can be different from their own. By age four or five, most children are in possession of at least a firstorder theory of mind (for a more complete review of development from age three to five, see Wellman, 1993). These stages can be conceived of as being some of the earliest phases of social development undergone by a child.

When considering the path of development outlined by Wellman (1993) with respect to children with ASD, several points become apparent. The first is that infants with ASD do not orient selectively to people (Frith, 2003). In fact, Frith provides evidence to suggest that children with ASD seem to preferentially attend to inanimate objects over human individuals. Since children with ASD are less likely to orient to people, they are less likely to learn from reciprocal interactions with their caregivers. This also means that they may, at best, be delayed in the development of the concept of other people having minds, and, at worst, never develop a theory of mind at all. Joint gaze, joint attention, and social referencing, which all serve as sources of social information for normal children (Wellman, 1993) have been found to be impaired in children with ASD. Again, this puts them at a disadvantage with respect to understanding that other people are intentional agents, and further delays or impairs their development of a theory of mind. As discussed above, pretense appears to rely on the 
understanding that people can have different perspectives to the same event or object; since individuals with ASD do not understand this, it comes as no surprise that they are also impaired in their ability to pretend, one indicator of which is symbolic play. Further, as mentioned in the introduction, pretense is a second-order function, something that children with ASD appear to have particular difficulty with (Baron-Cohen, 1987; Leslie, 1987).

Interaction between Social Development and Expressive Language

Finally, the results of this study revealed the possibility that expressive language may mediate the relationship between social development and symbolic play. The mediational model was selected to be in this direction, with expressive language acting as the mediator of the relationship between social development and symbolic play, due to the developmental progression of these skills. Social interaction appears earlier in development than does language ability, especially expressive language. Only in the older children who have already acquired expressive language would social development make logical sense as a mediator of the relationship between expressive language and symbolic play. Many of the children in this study had only minimal expressive language abilities. The current study therefore examined expressive language as a mediator of the relationship between social development and symbolic play.

Children who are socially impaired, possibly as a result of impaired selective orientation in infancy, would have fewer social opportunities for conversation, and would therefore have less well developed expressive language abilities. Further, given that children with ASD are less likely to orient to other people, they would be less likely to learn observationally from the conversations of other individuals, and so would not pick 
up expressive language to the same extent as might sociable children. The deficit in expressive language may translate into difficulties with the independent generation of symbolic representations, be they linguistic or playful. Thus, the impairment in social ability likely may lead to a lack of understanding of multiple perspectives, which is then related to a deficit in symbolic play. As well, social deficits may lead to impaired expressive language, which then, possibly though an impairment in the generation of symbols, is manifest as a further impairment in symbolic play.

\section{Clinical Implications}

The findings of this study would suggest that high and low functioning children with ASD might be distinct subgroups and should be seen as such. This finding is not unique to this study, and underscores the importance of the level of competence of children with ASD in determining outcomes. It also parallels previous research that found the same split between high and low cognitive functioning in relation to age of onset of ear infections and maternal language use (Konstantareas \& Homatidis, 1987; Konstantareas, Zajdeman, Homatidis, \& McCabe, 1988). Konstantareas and Homatidis (1987) suggested that this might be due to the greater central nervous system vulnerability of individuals with ASD at the lower functioning end of the spectrum. It is therefore crucial that future research be conducted on a broad sample of ASD individuals, comparing high and low abilities levels within ASD. This would allow research to better represent the entire spectrum, and also inform clinicians about necessary differences in interventions with both high and low functioning individuals.

This study also suggested that it is crucial to examine several domains of functioning within the same group of children in order to see how each domain affects 
the others. The results indicated that nonverbal cognitive ability, social skills, and expressive language skills are interrelated and that several skills uniquely contribute to symbolic play. Further research that investigates any of these domains should examine the interactions between them. This could be done by following a cohort of children with ASD through major transitions in life, such as during the language acquisition phase, to see the effects that increased language ability has on these other domains.

One of the areas of intervention that this study can inform is that of symbolic play. There is evidence that symbolic play can be taught (e.g., Stahmer, 1995). Such efforts will likely be more successful when attempted with higher functioning rather than lower functioning individuals with ASD. In early to middle childhood, appropriate play is associated with increased peer acceptance and popularity (Fein, 1981), and is therefore an important skill for children at this age. Thus, work on social interaction skills should be given priority with children presenting with ASD characteristics. When engaging the lower functioning children with ASD in play instruction, more intrusive attempts may need to be made if they are to benefit to the same degree as their higher functioning counterparts.

\section{Limitations}

One limitation to the current study is that the data were collected over a period of 10 years, from 1982 to 1992 . At the beginning of this period, the DSM-III was being employed, which then underwent a revision and was reprinted as the DSM-III-R in 1987. Therefore, diagnoses for the children in this study were determined by two different versions of the DSM. However, the criteria for ASD have remained highly comparable over the years, and as such this does not appear to be a major confounding issue in this 
study. Indeed, all the CARS scores of the children, another dimensional means of collecting diagnostic information, are definitely within the range for ASD.

Another limitation is in the tool used to measure symbolic play. The test used was geared towards younger children, with toys that are attractive to children between 12 and 36 months. Many of the children in this sample were older than 36 months, which may indicate that the toys were not of interest to these children. However, this would only have been an issue with the older, higher functioning children. Even within this group of children, there was no indication that the children found the toys to be below their interest level, as there were some high functioning children who were able to engage with the toys in an appropriate manner.

As with any study that employs correlational analyses, a third limitation of this study is that the nature of these analyses prevents the formation of causal conclusions. In order for a causal or directional conclusion to be confirmed, longitudinal studies must be conducted with analyses that permit such conclusions. Thus, while this study identified relationships between symbolic play and other developmental domains, it cannot lead to conclusions regarding the causal direction of these relationships.

\section{Future Directions}

This study found that expressive language acted as a mediator of the relationship between social development and symbolic play. However, due to the fact that the study employed a within participants, single sampling time design, there are limited conclusions that can be drawn regarding the developmental model linking these three constructs. A longitudinal study following the same cohort of children with ASD from early infancy through at least early childhood will be essential in determining the early 
correlates of abnormal development. Were such a study to be conducted, it would enable researchers to draw firmer conclusions regarding the path of development followed by children with ASD as compared with their counterparts who are normally developing or present with mental retardation or other developmental disabilities. Research of this nature would also permit further investigation into the effects of disruptions in early social and affective interactions on later language and play development.

It was also found that there was a difference between high and low functioning children with ASD. This finding suggests that it may be necessary to examine existing literature to see if previously identified empirical results are generalizable to all children with ASD, or whether they are specific to individuals who are functioning at the higher end of the spectrum. Along the same lines, it would also be beneficial to examine these relationships in normally developing children to see if they hold true in a non-ASD population.

\section{Conclusions}

Autistic Spectrum Disorder has been the focus of much research since its first identification by Leo Kanner (1943). Previous studies have linked the poor symbolic play ability of children with ASD to verbal and nonverbal cognitive ability, to expressive or receptive language, and to social development. As mentioned earlier, most of these studies have employed small samples and examined the role of one or at most a few variables. The results of this study, which was based on a large number of children with ASD of a wide range of abilities, indicated that the degree of impairment in spontaneous symbolic play seen in many children with ASD regardless of age, may be part and parcel of their other deficits in other areas of functioning such as nonverbal cognitive ability, 
expressive language, and social ability. Nonverbal cognitive ability was found to be the strongest predictor of symbolic play skills, followed by autistic symptomatology. Expressive, but not receptive, language was significantly related to symbolic play skills. Further, social development was related to symbolic play, but only in the higher functioning children, not in the lower functioning group. The relationship between social development and symbolic play appeared to be mediated by expressive language. Thus, the present findings provide support for the notion that there are interrelations between developmental domains in children with ASD, and that impairments in one area relate to performance in other areas. 


\section{References}

Alpern, G. D., Boll, T. J., \& Shearer, M. S. (1980). Developmental Profile II Manual. Colorado: Psychological Development Publications.

American Psychological Association. (2000). Diagnostic and Statistical Manual of Mental Disorders, Fourth Edition, Text Revision (DSM-IV-TR). Washington: APA.

Arthur, G. (1980). Instruction Manual: Arthur Adaptation of the Leiter International Performance Scale. Chicago: Stoelting Company.

Baron, R. M. \& Kenny, D. A. (1986). The moderator-mediator variable distinction in social psychological research: Conceptual, strategic, and statistical considerations. Journal of Personality and Social Psychology, 51, 1173-1182.

Baron-Cohen, S. (1987). Autism and symbolic play. British Journal of Developmental Psychology, 5, 139-148.

Baron-Cohen, S., Leslie, A. M., \& Frith, U. (1985). Does the autistic child have a "theory of mind"? Cognition, 21, 37-46.

Dawson, G., Meltzoff, A. N., Osterling, J., \& Rinaldi, J. (1998). Neuropsychological correlates of early symptoms of autism. Child Development, 69, 1276-1285.

Dunn, L. M. \& Dunn, L. M. (1981). Manual for the Peabody Picture Vocabulary TestRevised, forms $L$ and $M$. Minnesota: American Guidance Service.

Eaves, R. C. \& Milner, B. (1993). The criterion-related validity of the Childhood Autism Rating Scale and the Autism Behavior Checklist. Journal of Abnormal Child Psychology, 21, 481-491. 
El'Konin, D. B. (1999). The development of play in preschoolers. Journal of Russian and East European Psychology, 37, 31-70.

Fein, G. G. (1981). Pretend play in childhood: An integrative review. Child Development, 52, 1095-1118.

Fein, D., Pennington, B., Markowitz, P., Braverman, M., \& Waterhouse, L. (1986). Toward a neuropsychological model of infantile autism: Are the social deficits primary? Journal of the American Academy of Child Psychiatry, 25, 198-212.

Fombonne, E. (1998). Epidemiological surveys of autism. In F. R. Volkmar (Ed), Autism and Pervasive Developmental Disorders (pp. 32-63). Cambridge: Cambridge University Press.

Fombonne, E. (1999). The epidemiology of autism: a review. Psychological Medicine, 29, 769-786.

Frith, U. (2003). Autism: Explaining the Enigma. Massachusetts: Blackwell Publishing. Garfin, D. G., McCallon, D., \& Cox, R. (1988). Validity and reliability of the Childhood Autism Rating Scale with autistic adolescents. Journal of Autism and Developmental Disorders, 18, 367-378.

Göncü, A. Patt, M. B. \& Kouba, E. (2002). Understanding young children's pretend play in context. In P. K. Smith \& C. H. Hart (Eds.), Blackwell Handbook of Childhood Social Development (pp. 418-437). Massachusetts: Blackwell Publishers.

Gould, J. (1986). The Lowe and Costello Symbolic Play Test in socially impaired children. Journal of Autism and Developmental Disorders, 16, 199-213. 
Hobson, P. R. (1989). On sharing experiences. Development and Psychopathology, 1, 197-203.

Hobson, P. R. (1990). On acquiring knowledge about people and the capacity to pretend: Response to Leslie (1987). Psychological Review, 97, 114-121.

Jarrold, C., Boucher, J., \& Smith, P. (1993). Symbolic play in autism: A review. Journal of Autism and Developmental Disorders, 23, 281-307.

Kanner, L. (1943). Autistic disturbances of affective contact. Nervous Child, 2, 217250.

Klinger, L. G., Dawson, G., \& Renner, P. (2003). Autistic Disorder. In E. J. Mash \& R. A. Barkley (Eds.), Child Psychopathology, Second Edition (pp. 409-454). New York: Guilford.

Konstantareas, M. M. \& Homatidis, S. (1987). Brief report: Ear infections in autistic and normal children. Journal of Autism and Developmental Disorders, 17, 585594.

Konstantareas, M. M. \& Homatidis, S. (1999). Chromosomal abnormalities in a series of children with autistic disorder. Journal of Autism and Developmental Disorders, 29, 275-285.

Konstantareas, M. M., Zajdeman, H., Homatidis, S., McCabe, A. (1988). Maternal speech to verbal and higher functioning versus nonverbal and lower functioining and lower functioning autistic children. Journal of Autism and Developmental Disorders, 18, 647-656.

Laasko, M. -L., Poikkeus, A. -M, Eklund, K., \& Lyytinen, P. (1999). Social interactional behaviors and symbolic play competence as predictors of language 
development and their associations with maternal attention-directing strategies. Infant Behavior \& Development, 22, 541-556.

Leekam, S. \& Moore, C. (2001). The development of attention and joint attention in children with autism. In J. A. Burack, T. Charman, N. Yirmiya, \& P. R. Zelazo (Eds.) The Development of Autism: Perspectives from Theory and Research (pp. 105-129). New Jersey: Lawrence Erlbaum Associates.

Leslie, A. (1987). Pretense and representation: The origins of "Theory of Mind." Psychological Review, 94, 412-426.

Lewis, V. \& Boucher, J. (1988). Spontaneous, instructed and elicited play in relatively able autistic children. British Journal of Developmental Psychology, 6, 325-339.

Libby, S., Powell, S., Messer, D., \& Jordan, R. (1998). Spontaneous play in children with autism: A reappraisal. Journal of Autism and Developmental Disorders, 28, 487-497.

Lord, C., Rutter, M., DiLavore, P. C., \& Risi, S. (1999). Autism Diagnostic Observation Schedule - WPS (ADOS-WPS), Los Angeles, CA: Western Psychological Services.

Lowe, M. \& Costello, A. J. (1976). Manual for the Symbolic Play Test. Windsor: National Foundation for Educational Research.

Matson, J. L., Smiroldo, B. B., \& Hastings, T. L. (1998). Validity of the Autism/Pervasive Developmental Disorder subscale of the Diagnostic Assessment for the Severely Handicapped-II. Journal of Autism and Developmental Disorders, $28,77-81$. 
Mundy, P., Sigman, M., Ungerer, J., \& Sherman, T. (1987). Nonverbal communication and play correlates of language development in autistic children. Journal of Autism and Developmental Disorders, 17, 349-364.

Musatti, T., Veneziano, E., \& Mayer, S. (1998). Contributions of language to early pretend play. Current Psychology of Cognition, 17, 155-184.

Piaget, J. (1952). The Origins of Intelligence in Children. New York: International Universities Press, Inc.

Piaget, J. (1962). Play, Dreams and Imitation in Childhood. London: Routledge \& Kegan Paul Ltd.

Pilowsky, T., Yirmiya, N., Shulman, C., \& Dover, R. (1998). The Autism Diagnostic Interview-Revised and the Childhood Autism Rating Scale: Differences between diagnostic systems and comparison between genders. Journal of Autism and Developmental Disorders, 28, 143-151.

Power, T. J. \& Radcliffe, J. (1989). The relationship of play behavior to cognitive ability in developmentally disabled preschoolers. Journal of Autism and Developmental Disorders, 19, 97-107.

Reynell, J. (1977). Reynell Developmental Language Scales (Revised). London: National Foundation for Educational Research.

Reynell, J. \& Huntley, M. (1985). Reynell Developmental Language Scales Manual, Second Revision. Windsor: National Foundation for Educational Research Nelson. 
Riguet, C. B., Taylor, N. D., Benaroya, S., \& Klein, L. S. (1981). Symbolic play in autistic, Down's, and normal children of equivalent mental age. Journal of Autism and Developmental Disorders, 11, 439-448.

Russell, C. L. \& Russnaik, R. N. (1981). Language and symbolic play in infancy: Independent or related abilities? Canadian Journal of Behavioural Science, 13, 95-104.

Rutter, M. (1983). Cognitive deficits in the pathogenesis of autism. Journal of Child Psychology and Psychiatry, 24, 513-531.

Schopler, E., Reichler, R. J., DeVellis, R. F., \& Daly, K. (1980). Toward objective classification of childhood autism: Childhood Autism Rating Scale (CARS). Journal of Autism and Developmental Disorders, 10, 91-103.

Sevin, J. A., Matson, J. L., Coe, D. A., Fee, V. E., \& Sevin, B. M. (1991). A comparison and evaluation of three commonly used autism scales. Journal of Autism and Developmental Disorders, 21, 417-432.

Shah, A. \& Holmes, N. (1985). Brief report: The use of the Leiter International Performance Scale with autistic children. Journal of Autism and Developmental Disorders, 15, 195-203.

Sigman, M. \& Ungerer, J. A. (1984a). Attachment behaviors in autistic children. Journal of Autism and Developmental Disorders, 14, 231-244.

Sigman, M. \& Ungerer, J. A. (1984b). Cognitive and language skills in autistic, mentally retarded, and normal children. Developmental Psychology, 20, 293-302.

Silva, P. A. (1986). A comparison of the predictive validity of the Reynell Developmental Language Scales, the Peabody Picture Vocabulary Test and the 
Stanford-Binet Intelligence Scale. British Journal of Educational Psychology, 56, 302-204.

Spencer, P. E. (1996). The association between language and symbolic play at two years: Evidence from deaf toddlers. Child Development, 67, 867-876.

Stahmer, A. C. (1995). Teaching symbolic play skills to children with autism using Pivotal Response Training. Journal of Autism and Developmental Disorders, 25, 123-141.

Sturmey, P., Matson, J. L., \& Sevin, J. A. (1992). Brief report: Analysis of the internal consistency of three autism scales. Journal of Autism and Developmental Disorders, 22, 321-328.

Teal M. B. \& Wiebe, M. J. (1986). A validity analysis of selected instruments used to assess autism. Journal of Autism and Developmental Disorders, 16, 485-494.

Udwin, O. \& Yule, W. (1982). Validational data on Lowe and Costello's Symbolic Play Test. Child: care, health and development, 8, 361-366.

Ungerer, J. A. \& Sigman, M. (1984). The relation of play and sensorimotor behavior to language in the second year. Child Development, 55, 1448-1455.

Uzgiris, I. C. \& Hunt, J. M. (1976). Assessment in Infancy: Ordinal Scales of Psychological Development. Chicago: University of Illinois Press.

Vandenberg, B. (1978). Play and development from an ethological perspective. American Psychologist, 33, 724-738.

Vondra, J. \& Belsky, J. (1991). Infant play as a window on competence and motivation. In C. E. Schaefer, K. Gitlin, \& A. Sandgrund (Eds.), Play Diagnosis and Assessment (pp. 13-38). Toronto: John Wiley \& Sons. 
Wellman, H. M. (1993). Early understanding of mind: The normal case. In S. BaronCohen, H. Tager-Flusberg, \& D. J. Cohen (Eds.), Understanding Other Minds: Perspectives from Autism (pp. 10-39). Oxford: Oxford University Press.

Whyte, J. \& Owens, A. (1989). Language and symbolic play: Some findings from a study of autistic children. The Irish Journal of Psychology, 10, 317-332.

Wing, L., Gould, J., Yeates, S. R., \& Brierley, L. M. (1977). Symbolic play in severely mentally retarded and in autistic children. Journal of Child Psychology and Psychiatry, 18, 167-178. 
Appendix A

Parent Consent Form

We are interested in studying: (1) the life-long challenge parents such as yourselves experience in raising their children, (2) some of the factors contributing to the developmental delays. Specifically, we wish to establish differences and possible similarities in the challenges faced by parents of both normal and developmentally delayed children.

The information we are gathering involves how you perceive specific issues related to the raising of your child, what activities you engage in, and what appears to be helpful to you in your parenting. To get this information we will use questionnaires you fill in yourself or we will ask you to provide us information on your child-related activities. We need to know how each of the two parents independently understands and carries out his/her various responsibilities. We therefore would like to ask that both parents participate independently in the research. In addition, we will be testing and observing your child with respect to his/her characteristics, including his/her physical features and his/her behaviour. This information will relate specifically to our understanding of delayed development.

All information we gather will be kept in strict confidence and will be accessible only to the 3 people directly involved with the project. To our knowledge, there are no risks whatsoever in the procedures we are going to employ. Regarding benefits, we believe that the information you provide us will be valuable in the planning of relevant support systems for parents. In addition, at the end, we will briefly share with you our findings from your child's testing.

We are not examining individual responses but rather wish to understand the information provided by the entire group.

We should greatly appreciate your participation in this study. We believe that the maximum time required for answering our questionnaires will not exceed $3 \frac{1}{2}$ hours. Should you wish to interrupt your participation at any time you are free to do so. If you wish to participate, please sign the form below.

I, agree to participate in this project conducted by Dr. M. Konstantareas and Ms. S. Homatidis. I understand that I may withdraw from it at any time.

Signature (Father)

Signature (Mother)

Date

Witness 
Appendix B

Scoring sheet for the Lowe and Costello Symbolic Play Test

\begin{tabular}{|c|c|c|c|c|}
\hline Situation & Item No. & Description & Score & Observations \\
\hline \multirow[t]{5}{*}{$\bar{I}$} & 1 & Discriminates doll & & \\
\hline & 2 & Relates spoon to cup or saucer & & \\
\hline & 3 & Feeds/combs/brushes self/other person & & \\
\hline & 4 & Feeds/combs/brushes doll & & \\
\hline & 5 & Places cup on saucer & & \\
\hline \multirow[t]{5}{*}{ II } & 6 & Discriminates doll & & \\
\hline & 7 & Relates doll to bed & & \\
\hline & 8 & Relates blanket pillow to doll & & \\
\hline & 9 & Puts doll to bed & & \\
\hline & 10 & Pillow correct & & \\
\hline \multirow[t]{8}{*}{ III } & 11 & Relates knife/fork to plate & & \\
\hline & 12 & Relates fork $/ \mathrm{knife} /$ plate to table & & \\
\hline & 13 & Relates tablecloth to other object & & \\
\hline & 14 & Places doll on chair & & \\
\hline & 15 & Relates fork $/ \mathrm{knife} /$ plate to doll & & \\
\hline & 16 & Relates chair to table & & \\
\hline & 17 & Relates doll to table & & \\
\hline & 18 & Places tablecloth on table & & \\
\hline \multirow[t]{7}{*}{ IV } & 19 & Moves tractor/trailer along & & \\
\hline & 20 & Relates $\log (\mathrm{s})$ to tractor/trailer/man & & \\
\hline & 21 & Places man in tractor/trailer & & \\
\hline & 22 & Places man in driver's seat & & \\
\hline & 23 & Lines up tractor-trailer & 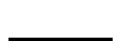 & \\
\hline & 24 & Attaches tractor to trailer & & \\
\hline & & Total Score & & \\
\hline
\end{tabular}

